\title{
Irreversible loss of ice nucleation active sites in mineral dust particles caused by sulphuric acid condensation
}

\author{
R. C. Sullivan ${ }^{1}$, M. D. Petters ${ }^{1,2}$, P. J. DeMott ${ }^{1}$, S. M. Kreidenweis ${ }^{1}$, H. Wex $^{3}$, D. Niedermeier ${ }^{3}$, S. Hartmann ${ }^{3}$, \\ T. Clauss ${ }^{3}$, F. Stratmann ${ }^{3}$, P. Reitz ${ }^{4,5}$, J. Schneider ${ }^{4}$, and B. Sierau ${ }^{6}$ \\ ${ }^{1}$ Department of Atmospheric Science, Colorado State University, Fort Collins, CO 80523-1371, USA \\ ${ }^{2}$ Department of Marine Earth and Atmospheric Sciences, North Carolina State University, Raleigh, NC 27695, USA \\ ${ }^{3}$ Leibniz Institute for Tropospheric Research, 04318 Leipzig, Germany \\ ${ }^{4}$ Particle Chemistry Department, Max Planck Institute for Chemistry, 55128 Mainz, Germany \\ ${ }^{5}$ Institute for Atmospheric Physics, Johannes Gutenberg University, 55099 Mainz, Germany \\ ${ }^{6}$ ETH Zürich, Institute for Atmospheric and Climate Science, 8092 Zürich, Switzerland
}

Received: 22 June 2010 - Published in Atmos. Chem. Phys. Discuss.: 8 July 2010

Revised: 29 November 2010 - Accepted: 30 November 2010 - Published: 3 December 2010

\begin{abstract}
During the FROST-2 (FReezing Of duST) measurement campaign conducted at the Leipzig Aerosol Cloud Interaction Simulator (LACIS), we investigated changes in the ice nucleation properties of $300 \mathrm{~nm}$ Arizona Test Dust mineral particles following thermochemical processing by varying amounts and combinations of exposure to sulphuric acid vapour, ammonia gas, water vapour, and heat. The processed particles' heterogeneous ice nucleation properties were determined in both the water subsaturated and supersaturated humidity regimes at $-30^{\circ} \mathrm{C}$ and $-25^{\circ} \mathrm{C}$ using Colorado State University's continuous flow diffusion chamber. The amount of sulphuric acid coating material was estimated by an aerosol mass spectrometer and from $\mathrm{CCN}$-derived hygroscopicity measurements. The condensation of sulphuric acid decreased the dust particles' ice nucleation ability in proportion to the amount of sulphuric acid added. Heating the coated particles in a thermodenuder at $250^{\circ} \mathrm{C}$ - intended to evaporate the sulphuric acid coating - reduced their freezing ability even further. We attribute this behaviour to accelerated acid digestion of ice active surface sites by heat. Exposing sulphuric acid coated dust to ammonia gas produced particles with similarly poor freezing potential; however a portion of their ice nucleation ability could be restored after heating in the thermodenuder. In no case did any combination of thermochemical treatments increase the ice nucleation ability of the coated mineral dust particles
\end{abstract}

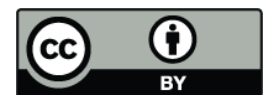

Correspondence to: R. C. Sullivan (rsullivan@atmos.colostate.edu) compared to unprocessed dust. These first measurements of the effect of identical chemical processing of dust particles on their ice nucleation ability under both water subsaturated and mixed-phase supersaturated cloud conditions revealed that ice nucleation was more sensitive to all coating treatments in the water subsaturated regime. The results clearly indicate irreversible impairment of ice nucleation activity in both regimes after condensation of concentrated sulphuric acid. This implies that the sulphuric acid coating caused permanent chemical and/or physical modification of the ice active surface sites; the possible dissolution of the coating during droplet activation did not restore all immersion/condensation-freezing ability.

\section{Introduction}

Mineral dust particles are some of the most efficient heterogeneous ice nuclei measured in laboratory studies, able to nucleate ice at higher temperatures and lower ice supersaturations than other non-biological particle compositions. They are frequently detected in ice crystal residues and thus thought to play an important role in ice cloud microphysics (Cantrell and Heymsfield, 2005; DeMott et al., 2003a, b; Stith et al., 2009). The ice nucleating ability of mineral dust depends on its mineralogy, with aluminosilicate mineral phases typically displaying some of the highest freezing potential (Archuleta et al., 2005; Eastwood et al., 2008; Kanji et al., 2008; Welti et al., 2009; Zimmermann et al., 2008). In general, larger dust particles can nucleate

Published by Copernicus Publications on behalf of the European Geosciences Union. 
ice at higher temperatures and lower ice supersaturations due to their larger surface area (Archuleta et al., 2005; Kanji et al., 2008; Phillips et al., 2008; Welti et al., 2009). Two principle mechanisms of heterogeneous ice nucleation by insoluble nuclei such as mineral dust are deposition and immersion/condensation-freezing ice nucleation (Cantrell and Heymsfield, 2005; Vali, 1985). Depositionmode ice nucleation involves the direct formation of ice on a particle's surface in contact with an ice supersaturated vapour, and therefore is expected to be the primary ice nucleation mode for bare mineral surfaces below water saturation. Immersion/condensation-freezing ice nucleation occurs when liquid droplets that contain an insoluble ice nucleus freeze. This process typically requires conditions above water saturation to occur, although particles with sufficient hygroscopicity may begin to freeze via this mechanism below water saturation at sufficiently low temperatures. Heterogeneous ice nucleation allows atmospheric mineral dust particles to freeze under warmer conditions and lower water relative humidities than those required to freeze aqueous salt particles, which form ice via homogeneous nucleation only at temperatures below $-38^{\circ} \mathrm{C}$ (Cantrell and Heymsfield, 2005; Martin, 2000). Thus, the presence or lack of mineral dust particles in an air parcel at any time may alter the conditions for ice formation under mixed-phase and cirrus cloud conditions. The microphysical effects of ice nuclei can produce a change in top of the atmosphere radiative forcing, stimulate precipitation through cloud glaciation, influence cloud structure and lifetime, and facilitate heterogeneous chemical reactions of trace gases (Abbatt, 2003; Baker, 1997; Cantrell and Heymsfield, 2005; Lohmann and Feichter, 2005).

Individual atmospheric mineral dust particles are commonly observed to have accumulated secondary soluble material during atmospheric transport (Russell et al., 2002; Shi et al., 2008; Sullivan et al., 2007; Sullivan and Prather, 2007). The addition of secondary material to dust particles that occurs during atmospheric processing - via coagulation, condensation, cloud processing, and heterogeneous reactions - can potentially modify and impair the ice nucleation ability of atmospheric dust particles. Such effects have been observed in laboratory studies of dust particles coated by sulphuric acid or secondary organic aerosol (SOA) material (Archuleta et al., 2005; Cziczo et al., 2009; Eastwood et al., 2009; Möhler et al., 2008; Niedermeier et al., 2010a). The addition of secondary compounds can shift a dust particle's ice nucleation mechanism from deposition to immersion/condensation-freezing below water saturation at $T>-38^{\circ} \mathrm{C}$, often leading to apparent or real reduction in the heterogeneous ice nucleation ability of the mineral dust. However, there are a few observations reported where such treatments have resulted in no change or even an increase in the dust's freezing ability (Archuleta et al., 2005; Eastwood et al., 2009; Knopf and Koop, 2006; Salam et al., 2007).

Here we investigate some important open questions regarding the effect of coatings on heterogeneous ice nucle- ation including: (1) the ice nucleation response to the same chemical processing in the water subsaturated versus supersaturated regime, (2) the reversibility of changes in ice nucleation behaviour induced by the addition and removal of particle coatings, and (3) the effect of converting sulphuric acid coatings to ammonium sulphate salts. These experiments were performed as part of the FROST-2 (FReezing Of duST) study conducted at the Leipzig Aerosol Cloud Interactions Simulator (LACIS) facility. Results from the related FROST-1 experiments are described by Niedermeier et al. (2010a). A novel aspect of the study presented here is the assessment of the same chemical treatments on ice nucleation both below and above water saturation in the heterogeneous ice nucleation regime warmer than $-38^{\circ} \mathrm{C}$.

\section{Experimental methods}

\subsection{Mineral particle generation}

Arizona Test Dust (ATD: ISO12103-1, A1 Ultrafine Test Dust, Powder Technology Inc., Burnsville, Minnesota, USA) mineral particles were used in all experiments. ATD is a manufactured mineral dust intended to represent typical chemical and physical properties of desert dust common to the south-western United States. ATD particles have low hygroscopicity $\left(\kappa_{\text {app }}=0.003-0.025\right)$ as determined by water uptake properties below and above water saturation (Herich et al., 2009; Koehler et al., 2009; Vlasenko et al., 2005). At cirrus temperatures below $-38^{\circ} \mathrm{C}$, deposition ice nucleation of ATD occurs above an ice supersaturation threshold of 110-115\% (Knopf and Koop, 2006; Möhler et al., 2006), with larger submicron particles nucleating at modestly lower ice supersaturation than smaller particles (Koehler, 2007; Welti et al., 2009). These ice nucleation properties are similar to those observed for various pure aluminosilicate minerals (Connolly et al., 2009; Eastwood et al., 2008; Kanji et al., 2008; Möhler et al., 2006, 2008; Zimmermann et al., 2008). The bulk chemical composition of the resuspended ATD powder was found to be $\sim 80 \%$ aluminosilicates by mass, $5 \%$ each of $\mathrm{Fe}, \mathrm{Ca}$, and $\mathrm{Mg}$ (Vlasenko et al., 2005); the latter two elements can be attributed to the presence of alkaline $\mathrm{CaCO}_{3}$ and $\mathrm{MgCa}\left(\mathrm{CO}_{3}\right)_{2}$. ATD aerosol was suspended dry by a fluidized bed generator (TSI3400A, TSI Inc., St. Paul, Minnesota, USA) and passed through an in-house corona discharge source. The corona discharge did not change the IN ability (Niedermeier et al., 2010a). Particles larger than $560 \mathrm{~nm}$ in aerodynamic diameter were removed by a Micro-Orifice Uniform-Deposition Impactor (MOUDI: Model 100R, MSP Corporation, Shoreview, Michigan, USA). The remaining aerosol was passed through a $\mathrm{Kr}-85$ neutralizer. 


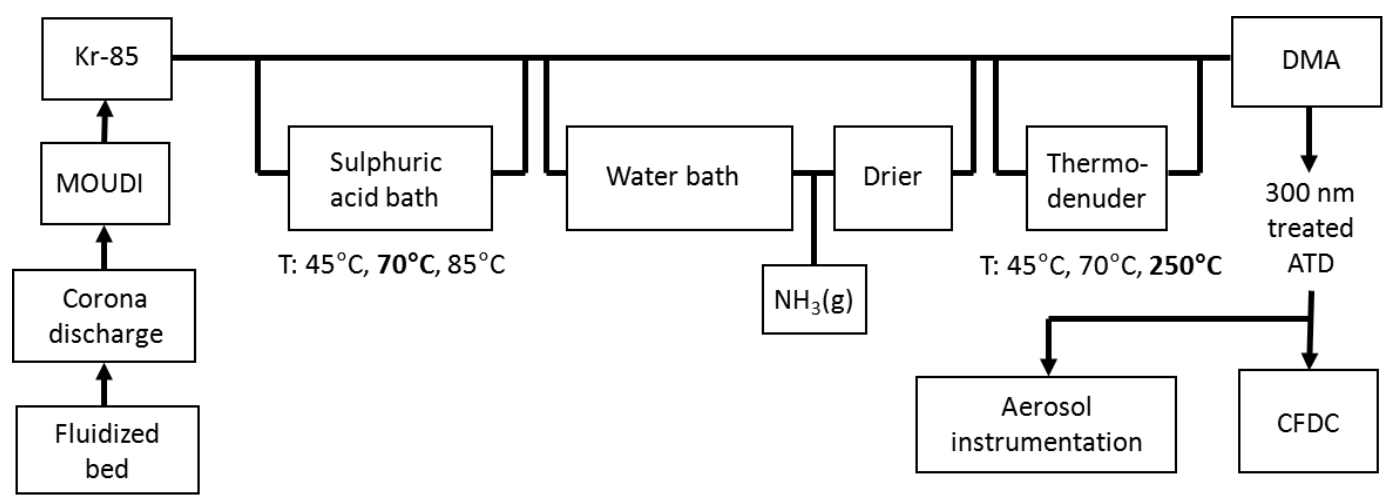

Fig. 1. Schematic of dust aerosol generation, treatment, and analysis system. Arizona Test Dust was generated dry from the fluidized bed, and then subjected to a variety of thermochemical treatment options. The most commonly used sequence of treatment options is shown here. Temperatures listed in bold were the default settings used in the sulphuric acid coating oven and thermodenuder. A differential mobility analyser (DMA) selected $300 \mathrm{~nm}$ mobility diameter particles after treatment for analysis by the CFDC and other instruments including the ATOFMS, AMS, and CCNc.

\subsection{Chemical processing of particles}

The ATD particles were subjected to a variety of chemical and physical treatments:

1. Coating with sulphuric acid (variable coating oven temperature: $45,70,85^{\circ} \mathrm{C}$ )

2. Heating in a thermodenuder (typically $250^{\circ} \mathrm{C}$, but 45 , 70 , and $85^{\circ} \mathrm{C}$ also used)

\section{Transport over a liquid water bath}

4. Exposure to ammonia gas

The most commonly used treatment sequence is outlined in Fig. 1, and is similar to that used by Niedermeier et al. (2010a). The principle treatment involved passing the aerosol through a heated vapour diffusion tube containing a reservoir of liquid sulphuric acid; upon cooling, sulphuric acid vapours condensed onto the particle surface. The amount of secondary material added to the dust particles was controlled by the tube's temperature. The tube was surrounded by a water jacket with temperature control of $\pm 0.1 \mathrm{~K}$. The thermodenuder consisted of a heated region with a residence time of 4-5 s followed by an unheated charcoal denuder and was intended to remove a portion of the sulphuric acid condensed on the particles. The water bath was used to explore the effect of hygroscopic water absorption immediately following the sulphuric acid particle coating. The aerosol's residence time over the water bath was about $70 \mathrm{~s}$. In some experiments, ammonia gas (10 ppm, Air liquide $\mathrm{GmbH}$, Leipzig, Germany) was added at a flow rate of $0.50 \mathrm{Lpm}$ to the aerosol flow to test the effect of neutralizing the sulphuric acid coating by conversion to ammonium sulphate. During the campaign we suspected that the branch used for the water bath exposure had become contaminated by the first ammonia exposure experiments. This may have exposed the ATD particles to an unknown concentration of ammonia gas when the water bath alone was subsequently used. As we cannot determine the degree of contamination, we do not discuss the experiments using the water bath here, though the data is listed in Table 1 . We do discuss the ammonia gas exposure experiments, in which particles were passed over the water bath before ammonia gas exposure in most cases. The AMS often detected ammonium in chemically treated particles when ammonia gas was not added, but in most cases the ammonium mass was below the quantification limit due to interference from oxygen and water. There may have been low levels of ammonia gas present in the compressed air carrier gas but we were unable to quantify this.

The sequential order of the treatments and the processing time was also changed in some cases; a total of 24 different treatment conditions were explored. Particles with a mobility diameter of $300 \mathrm{~nm}$ were selected from the processed polydisperse aerosol by a differential mobility analyzer (DMA) (Vienna "Medium Type" Model; sheath flow: $10 \mathrm{Lpm}$, aerosol flow: $1.0-1.5 \mathrm{Lpm})$. A condensation particle counter (CPC, Model 3010, TSI Inc.) measured the total concentration of size-selected particles $(\mathrm{CN})$ exiting the DMA. The monodisperse aerosol was then delivered to the various aerosol instruments. These included a hygroscopic growth tandem differential mobility analyzer (HTDMA) and cloud condensation nuclei counter (CCNc: Droplet Technologies Inc., Boulder, CO, USA) to determine the hygroscopicity of the treated particles and thus infer the coating volume fraction. An aerosol mass spectrometer (AMS) and aerosol time-of-flight mass spectrometer (ATOFMS) performed online measurements of bulk and single-particle chemical composition, respectively. Finally, four different ice nucleation instruments (LACIS, the Portable Ice Nucleus 
Table 1. IN fractions measured at $-30^{\circ} \mathrm{C}$ and $-25^{\circ} \mathrm{C}$ for Arizona Test Dust particles subjected to different treatment combinations $s^{\mathrm{a}}$, particle hygroscopicity and volume fraction of sulphuric acid estimated from $\mathrm{CCN}$ measurements ${ }^{\mathrm{b}}$, and sulphate mass per particle estimated from AMS measurements.

\begin{tabular}{|c|c|c|c|c|c|c|c|c|c|c|c|c|}
\hline Exp & $\mathrm{SA}\left({ }^{\circ} \mathrm{C}\right)$ & $\mathrm{TD}\left({ }^{\circ} \mathrm{C}\right)$ & WB & $\mathrm{NH}_{3}$ & $\begin{array}{c}\mathrm{IN} \\
\left(\mathrm{RH}_{\mathrm{W}}=98 \%\right)\end{array}$ & St Dev & $\begin{array}{c}\mathrm{IN} \\
\left(\mathrm{RH}_{\mathrm{W}}=105 \%\right)\end{array}$ & St Dev & $\mathrm{s}_{\mathrm{c}}(\%)$ & $\kappa_{\text {app }}$ & $\begin{array}{r}\mathrm{H}_{2} \mathrm{SO}_{4}(\mathrm{by} \\
\text { volume) }^{\mathrm{b}}\end{array}$ & $\begin{array}{r}\text { Sulphate } \\
\text { (ag/particle) }\end{array}$ \\
\hline \multicolumn{13}{|c|}{ Temperature $=-30^{\circ} \mathrm{C}$} \\
\hline 1.1 & & & & & & & $5.03 \times 10^{-2}$ & $8.69 \times 10^{-3}$ & 0.380 & 0.0021 & $2.01 \times 10^{-4}$ & $\mathrm{BDL}^{\mathrm{c}}$ \\
\hline $14 \mathrm{a}$ & & & & & $6.54 \times 10^{-3}$ & $2.93 \times 10^{-3}$ & & & 0.385 & 0.0020 & $4.30 \times 10^{-5}$ & \\
\hline $14 \mathrm{i}$ & & & & & $6.17 \times 10^{-3}$ & $2.19 \times 10^{-3}$ & & & & & & BDL \\
\hline $16 \mathrm{a}$ & & & & & & & $3.89 \times 10^{-2}$ & $8.23 \times 10^{-3}$ & & & & BDL \\
\hline $16 \mathrm{i}$ & & & & & & & $3.98 \times 10^{-2}$ & $5.33 \times 10^{-3}$ & & & & BDL \\
\hline 2.1 & & 250 & & & & & $3.52 \times 10^{-2}$ & $5.47 \times 10^{-3}$ & 0.390 & 0.0019 & $-8.60 \times 10^{-5}$ & BDL \\
\hline 13.1 & & 250 & & & $3.24 \times 10^{-3}$ & $1.54 \times 10^{-3}$ & $3.63 \times 10^{-2}$ & $5.36 \times 10^{-3}$ & 0.388 & 0.0020 & $-4.30 \times 10^{-5}$ & BDL \\
\hline $14 \mathrm{~b}$ & & 250 & & & $2.97 \times 10^{-3}$ & $1.91 \times 10^{-3}$ & & & & & & BDL \\
\hline $16 \mathrm{~b}$ & & 250 & & & & & $2.43 \times 10^{-2}$ & $6.03 \times 10^{-3}$ & & & & BDL \\
\hline 20 & & 45 & & & $3.59 \times 10^{-3}$ & $1.69 \times 10^{-3}$ & $2.83 \times 10^{-2}$ & $6.03 \times 10^{-3}$ & 0.388 & 0.0020 & $-2.87 \times 10^{-5}$ & BDL \\
\hline 21 & & 70 & & & $4.07 \times 10^{-3}$ & $2.64 \times 10^{-3}$ & $3.20 \times 10^{-2}$ & $6.56 \times 10^{-3}$ & 0.391 & 0.0019 & $-8.60 \times 10^{-5}$ & BDL \\
\hline $36 c$ & & 85 & & & & & $2.99 \times 10^{-2}$ & $4.53 \times 10^{-3}$ & & & & \\
\hline $29 \mathrm{j}$ & & & $\mathrm{x}$ & $\mathrm{X}$ & & & $2.86 \times 10^{-2}$ & $6.52 \times 10^{-3}$ & & & & BDL \\
\hline 3.1 & 45 & & & & $1.97 \times 10^{-4}$ & $3.64 \times 10^{-4}$ & $2.48 \times 10^{-2}$ & $4.99 \times 10^{-3}$ & 0.177 & 0.0165 & $2.08 \times 10^{-2}$ & 951 \\
\hline $14 \mathrm{~d}$ & 45 & & & & $4.42 \times 10^{-5}$ & $1.78 \times 10^{-4}$ & & & & & & 688 \\
\hline $16 \mathrm{~d}$ & 45 & & & & & & $2.69 \times 10^{-2}$ & $4.79 \times 10^{-3}$ & & & & 603 \\
\hline 19 & 45 & 45 & & & 0 & & $3.71 \times 10^{-3}$ & $2.64 \times 10^{-3}$ & 0.206 & 0.0116 & $1.38 \times 10^{-2}$ & 529 \\
\hline 22 & 70 & 70 & & & $2.75 \times 10^{-4}$ & $9.81 \times 10^{-4}$ & $2.69 \times 10^{-4}$ & $6.49 \times 10^{-4}$ & 0.151 & 0.0218 & $2.84 \times 10^{-2}$ & 1246 \\
\hline 4.1 & 45 & 250 & & & $2.58 \times 10^{-4}$ & $5.44 \times 10^{-4}$ & $1.60 \times 10^{-3}$ & $1.07 \times 10^{-3}$ & 0.226 & 0.0089 & $9.87 \times 10^{-3}$ & 527 \\
\hline $14 \mathrm{c}$ & 45 & 250 & & & $8.01 \times 10^{-5}$ & $2.89 \times 10^{-4}$ & & & & & & 0 \\
\hline $16 \mathrm{c}$ & 45 & 250 & & & & & $2.28 \times 10^{-3}$ & $1.38 \times 10^{-3}$ & & & & 451 \\
\hline 6.1 & 70 & & & & 0 & & $2.38 \times 10^{-3}$ & $1.32 \times 10^{-3}$ & 0.134 & 0.0281 & $3.74 \times 10^{-2}$ & 1871 \\
\hline $14 \mathrm{e}$ & 70 & & & & $3.10 \times 10^{-5}$ & $1.53 \times 10^{-4}$ & & & & & & 1842 \\
\hline $16 \mathrm{e}$ & 70 & & & & & & $7.81 \times 10^{-4}$ & $7.22 \times 10^{-4}$ & & & & 1637 \\
\hline $14 \mathrm{f}$ & 70 & 250 & & & $3.46 \times 10^{-5}$ & $1.79 \times 10^{-4}$ & & & & & & 995 \\
\hline $16 \mathrm{f}$ & 70 & 250 & & & & & $8.97 \times 10^{-5}$ & $2.65 \times 10^{-4}$ & & & & 896 \\
\hline 10.1 & 70 & & $\mathrm{x}$ & & 0 & & $6.26 \times 10^{-4}$ & $6.63 \times 10^{-4}$ & 0.120 & 0.0351 & $4.74 \times 10^{-2}$ & 2136 \\
\hline $14 \mathrm{~g}$ & 70 & & $\mathrm{X}$ & & $3.20 \times 10^{-5}$ & $1.75 \times 10^{-4}$ & & & & & & 1637 \\
\hline 17 & 70 & & $\mathrm{X}$ & & $1.13 \times 10^{-4}$ & $3.34 \times 10^{-4}$ & $4.12 \times 10^{-4}$ & $6.91 \times 10^{-4}$ & 0.127 & 0.0308 & $4.13 \times 10^{-2}$ & 1709 \\
\hline $16 \mathrm{~h}$ & 70 & & $\mathrm{X}$ & & & & $2.51 \times 10^{-4}$ & $4.12 \times 10^{-4}$ & & & & 1895 \\
\hline $34 \mathrm{a}$ & 70 & & $\mathrm{X}$ & & & & $3.34 \times 10^{-4}$ & $4.42 \times 10^{-4}$ & & & & 2033 \\
\hline $36 b$ & 70 & & $\mathrm{X}$ & & & & $8.46 \times 10^{-5}$ & $1.75 \times 10^{-4}$ & & & & 0 \\
\hline 11.1 & 70 & 250 & $\mathrm{x}$ & & $1.22 \times 10^{-4}$ & $4.25 \times 10^{-4}$ & $5.00 \times 10^{-3}$ & $2.56 \times 10^{-3}$ & 0.130 & 0.0297 & $3.97 \times 10^{-2}$ & 1764 \\
\hline $14 \mathrm{~g}$ & 70 & 250 & $\mathrm{X}$ & & $3.54 \times 10^{-5}$ & $2.02 \times 10^{-4}$ & & & & & & 1637 \\
\hline $16 \mathrm{~g}$ & 70 & 250 & $\mathrm{X}$ & & & & $2.15 \times 10^{-3}$ & $1.41 \times 10^{-3}$ & & & & 1604 \\
\hline 18 & 70 & 250 & $\mathrm{X}$ & & $3.93 \times 10^{-5}$ & $2.22 \times 10^{-4}$ & $3.77 \times 10^{-3}$ & $1.75 \times 10^{-3}$ & 0.137 & 0.0269 & $3.57 \times 10^{-2}$ & 1361 \\
\hline $23^{\mathrm{d}}$ & 70 & 250 & $\mathrm{X}$ & & 0 & & 0 & & 0.164 & 0.0187 & $2.39 \times 10^{-2}$ & 1145 \\
\hline 30.1 & 85 & & & & $4.82 \times 10^{-5}$ & $1.53 \times 10^{-4}$ & $1.27 \times 10^{-3}$ & $9.79 \times 10^{-4}$ & 0.064 & 0.1230 & $1.73 \times 10^{-1}$ & 2989 \\
\hline 31.1 & 85 & 250 & & & $8.79 \times 10^{-5}$ & $2.32 \times 10^{-4}$ & $9.89 \times 10^{-5}$ & $2.48 \times 10^{-4}$ & 0.138 & 0.0268 & $3.55 \times 10^{-2}$ & 1262 \\
\hline 24.1 & 70 & & $\mathrm{x}$ & $\mathrm{X}$ & $4.10 \times 10^{-5}$ & $2.05 \times 10^{-4}$ & $2.90 \times 10^{-4}$ & $6.83 \times 10^{-4}$ & 0.119 & 0.0356 & $4.81 \times 10^{-2}$ & 1625 \\
\hline 28.1 & 70 & & $\mathrm{X}$ & $\mathrm{X}$ & $6.40 \times 10^{-5}$ & $2.48 \times 10^{-4}$ & $4.10 \times 10^{-4}$ & $6.10 \times 10^{-4}$ & 0.131 & 0.0292 & $3.90 \times 10^{-2}$ & 1080 \\
\hline $34 \mathrm{~d}$ & 70 & & $\mathrm{X}$ & $\mathrm{X}$ & & & $1.57 \times 10^{-4}$ & $2.13 \times 10^{-4}$ & & & & 1621 \\
\hline 25.1 & 70 & 250 & $\mathrm{x}$ & $\mathrm{X}$ & $6.14 \times 10^{-4}$ & $1.10 \times 10^{-3}$ & $2.26 \times 10^{-3}$ & $2.17 \times 10^{-3}$ & 0.129 & 0.0298 & $3.98 \times 10^{-2}$ & 1354 \\
\hline $34 \mathrm{c}$ & 70 & 250 & $\mathrm{X}$ & $\mathrm{X}$ & & & $1.02 \times 10^{-3}$ & $7.30 \times 10^{-4}$ & & & & 1421 \\
\hline $34 \mathrm{e}$ & 85 & & $\mathrm{x}$ & & & & $3.39 \times 10^{-5}$ & $1.06 \times 10^{-4}$ & & & & 3652 \\
\hline $34 f$ & 85 & 250 & $\mathrm{X}$ & & & & $3.21 \times 10^{-4}$ & $4.91 \times 10^{-4}$ & & & & 2458 \\
\hline $34 \mathrm{~g}$ & 85 & 250 & $\mathrm{X}$ & $\mathrm{X}$ & & & $5.20 \times 10^{-4}$ & $5.22 \times 10^{-4}$ & & & & 2416 \\
\hline $34 \mathrm{~h}$ & 85 & & $\mathrm{X}$ & $\mathrm{X}$ & & & $4.55 \times 10^{-5}$ & $1.11 \times 10^{-4}$ & & & & 3363 \\
\hline $32.1^{\mathrm{e}}$ & 70 & & & & $4.99 \times 10^{-5}$ & $1.27 \times 10^{-4}$ & $6.42 \times 10^{-3}$ & $2.01 \times 10^{-3}$ & 0.136 & 0.0272 & $3.61 \times 10^{-2}$ & 1561 \\
\hline $33.1^{\mathrm{e}}$ & 70 & 250 & & & 0 & & $1.04 \times 10^{-4}$ & $2.14 \times 10^{-4}$ & 0.168 & 0.018 & $2.29 \times 10^{-2}$ & 0 \\
\hline $36 a .1$ & 70 & & & $\mathrm{x}$ & 0 & & $1.63 \times 10^{-4}$ & $2.19 \times 10^{-4}$ & & & & 2106 \\
\hline
\end{tabular}


Table 1. Continued.

\begin{tabular}{|c|c|c|c|c|c|c|c|c|c|c|c|c|}
\hline Exp & $\mathrm{SA}\left({ }^{\circ} \mathrm{C}\right)$ & $\operatorname{TD}\left({ }^{\circ} \mathrm{C}\right)$ & WB & $\mathrm{NH}_{3}$ & $\begin{array}{c}\mathrm{IN} \\
\left(\mathrm{RH}_{\mathrm{W}}=98 \%\right)\end{array}$ & St Dev & $\begin{array}{c}\mathrm{IN} \\
\left(\mathrm{RH}_{\mathrm{W}}=105 \%\right)\end{array}$ & St Dev & $\mathrm{s}_{\mathrm{c}}(\%)$ & $\kappa$ app & $\begin{array}{c}\mathrm{H}_{2} \mathrm{SO}_{4}(\mathrm{by} \\
\text { volume) }\end{array}$ & $\begin{array}{r}\text { Sulphate } \\
(\mathrm{ag} / \text { particle) }\end{array}$ \\
\hline \multicolumn{13}{|c|}{ Temperature $=-25^{\circ} \mathrm{C}$} \\
\hline 1.2 & & & & & $2.31 \times 10^{-4}$ & $4.65 \times 10^{-4}$ & $2.00 \times 10^{-2}$ & $3.93 \times 10^{-3}$ & 0.380 & 0.0021 & $2.01 \times 10^{-4}$ & BDL \\
\hline 12.2 & & & & & $7.15 \times 10^{-4}$ & $6.53 \times 10^{-4}$ & & & 0.382 & 0.0021 & $1.29 \times 10^{-4}$ & BDL \\
\hline 2.2 & & 250 & & & & & $1.37 \times 10^{-2}$ & $2.67 \times 10^{-3}$ & 0.390 & 0.0019 & $-8.60 \times 10^{-5}$ & BDL \\
\hline 13.2 & & 250 & & & $4.02 \times 10^{-4}$ & $5.12 \times 10^{-4}$ & $1.16 \times 10^{-2}$ & $2.71 \times 10^{-3}$ & 0.388 & 0.0020 & $-4.30 \times 10^{-5}$ & BDL \\
\hline 3.2 & 45 & & & & & & $1.33 \times 10^{-2}$ & $3.20 \times 10^{-3}$ & 0.177 & 0.0165 & $2.08 \times 10^{-2}$ & 671 \\
\hline 4.2 & 45 & 250 & & & $1.49 \times 10^{-4}$ & $3.48 \times 10^{-4}$ & $1.28 \times 10^{-3}$ & $8.19 \times 10^{-4}$ & 0.226 & 0.0089 & $9.87 \times 10^{-3}$ & 371 \\
\hline 6.2 & 70 & & & & & & $2.21 \times 10^{-3}$ & $1.22 \times 10^{-3}$ & 0.134 & 0.0281 & $3.74 \times 10^{-2}$ & 1318 \\
\hline 7.2 & 70 & 250 & & & $3.58 \times 10^{-4}$ & $6.55 \times 10^{-4}$ & $8.60 \times 10^{-4}$ & $8.14 \times 10^{-4}$ & 0.172 & 0.0174 & $2.21 \times 10^{-2}$ & 729 \\
\hline 10.2 & 70 & & $\mathrm{X}$ & & $2.17 \times 10^{-4}$ & $4.56 \times 10^{-4}$ & $3.64 \times 10^{-4}$ & $6.47 \times 10^{-4}$ & 0.120 & 0.0351 & $4.74 \times 10^{-2}$ & 1505 \\
\hline 11.2 & 70 & 250 & $\mathrm{X}$ & & & & $3.15 \times 10^{-3}$ & $2.26 \times 10^{-3}$ & 0.130 & 0.0297 & $3.97 \times 10^{-2}$ & 1243 \\
\hline 24.2 & 70 & & $\mathrm{X}$ & $\mathrm{X}$ & $1.25 \times 10^{-4}$ & $2.49 \times 10^{-4}$ & $6.36 \times 10^{-5}$ & $2.80 \times 10^{-4}$ & 0.119 & 0.0356 & $4.81 \times 10^{-2}$ & 1145 \\
\hline 28.2 & 70 & & $\mathrm{X}$ & $\mathrm{X}$ & $3.35 \times 10^{-5}$ & $1.25 \times 10^{-4}$ & $1.83 \times 10^{-5}$ & $9.23 \times 10^{-5}$ & 0.131 & 0.0292 & $3.90 \times 10^{-2}$ & 761 \\
\hline 25.2 & 70 & 250 & $\mathrm{X}$ & $x$ & $3.30 \times 10^{-4}$ & $6.73 \times 10^{-4}$ & $5.04 \times 10^{-4}$ & $9.50 \times 10^{-4}$ & 0.129 & 0.0298 & $3.98 \times 10^{-2}$ & 954 \\
\hline 30.2 & 85 & & & & $1.53 \times 10^{-5}$ & $7.97 \times 10^{-5}$ & $1.40 \times 10^{-4}$ & $2.50 \times 10^{-4}$ & 0.064 & 0.1230 & $1.73 \times 10^{-1}$ & 2106 \\
\hline 31.2 & 85 & 250 & & & $4.65 \times 10^{-5}$ & $1.46 \times 10^{-4}$ & $6.38 \times 10^{-5}$ & $1.72 \times 10^{-4}$ & 0.138 & 0.0268 & $3.55 \times 10^{-2}$ & 889 \\
\hline $32.2^{\mathrm{e}}$ & 70 & & & & $1.43 \times 10^{-5}$ & $7.16 \times 10^{-5}$ & $2.78 \times 10^{-5}$ & $9.62 \times 10^{-5}$ & 0.136 & 0.0272 & $3.61 \times 10^{-2}$ & 1100 \\
\hline $33.2^{\mathrm{e}}$ & 70 & 250 & & & $2.94 \times 10^{-5}$ & $1.10 \times 10^{-4}$ & $5.46 \times 10^{-5}$ & $1.44 \times 10^{-4}$ & 0.168 & 0.0180 & $2.29 \times 10^{-2}$ & \\
\hline $36 a .2$ & 70 & & & $\mathrm{X}$ & $6.95 \times 10^{-6}$ & $3.97 \times 10^{-5}$ & $2.78 \times 10^{-5}$ & $8.06 \times 10^{-5}$ & & & & 1484 \\
\hline
\end{tabular}

${ }^{a}$ Treatment order was sulphuric acid coating (SA), water bath $(\mathrm{WB})$, ammonia $\left(\mathrm{NH}_{3}\right)$, thermodenuder $(\mathrm{TD})$; if that component was used, unless otherwise indicated below. $\mathrm{b}$ See Eq. (2) ${ }^{c}$ Below detection limit ${ }^{\mathrm{d}}$ Order: $\mathrm{SA}+\mathrm{TD}+\mathrm{WB}{ }^{\mathrm{e}}$ Longer SA coating time.

Counter (PINC), the Fast Ice Nucleus Chamber (FINCH), and the Colorado State University (CSU) Continuous Flow Diffusion Chamber (CFDC)) sampled the aerosol and processed it at various temperatures and relative humidities to simulate ice nucleation as it might occur during cloud formation in the atmosphere. Here we present results on ice nuclei (IN) activated in the CSU CFDC, and complementary information on aerosol chemistry and hygroscopicity obtained by the AMS, ATOFMS, and CCN measurements.

\subsection{Ice nuclei measurements}

The CFDC consists of two cylindrical ice-coated temperature controlled walls (Petters et al., 2009; Rogers et al., 2001). The aerosol is passed through the $1.2 \mathrm{~cm}$ annulus between the two walls, surrounded by particle-free sheath air. By controlling the temperature of and gradient between the walls, the temperature, and water and ice vapour saturation ratios of the aerosol lamina can be controlled. Particles that are able to nucleate ice under the selected conditions grow to supermicron sizes and are counted by an optical particle counter (OPC) at the exit of the chamber. An evaporation region where the aerosol experiences ice saturation but water subsaturation lies in-between the main ice chamber and the OPC. This section evaporates activated cloud droplets so that they do not interfere with the optical detection of ice crystals. Above $\sim 107 \% \mathrm{RH}_{\mathrm{w}}$ (water relative humidity - the percentage ratio of water vapour pressure to saturated water vapour pressure over supercooled liquid water), depending on temperature, droplets do not fully evaporate before reaching the OPC and thus ice crystals and water droplets cannot be discriminated at these conditions. During an experiment the aerosol lamina temperature is held approximately constant while $\mathrm{RH}_{\mathrm{i}}$ (relative humidity with respect to ice) and $\mathrm{RH}_{\mathrm{w}}$ are scanned upwards (by increasing the temperature gradient) to determine the fraction of particles capable of nucleating ice as a function of $\mathrm{RH}_{\mathrm{W}}$ and $\mathrm{RH}_{\mathrm{i}}$ (Petters et al., 2009). Processing conditions were determined from the formulas given by Rogers (1988) using the saturation vapour pressure parameterization over supercooled water and ice from Buck (1981) ( $e_{\mathrm{w} 3}$ and $e_{\mathrm{i} 1}$ from his Table 2). Typical uncertainty in $\mathrm{RH}_{\mathrm{w}}$ is $\pm 3 \%$ (absolute) at $-30{ }^{\circ} \mathrm{C}$, while temperature uncertainty is $\pm 1^{\circ} \mathrm{C}$.

For all experiments the aerosol's freezing efficiency was determined from the ratio of IN measured by the CFDC to total $\mathrm{CN}$ measured by the CPC, $f_{\mathrm{IN}}=\mathrm{IN} / \mathrm{CN}$. In some experiments full scans from $\sim 75 \%$ to $\geq 110 \% \mathrm{RH}_{\mathrm{W}}$ were conducted at a rate of $\sim 1 \% \mathrm{RH}_{\mathrm{w}}$ per minute, while in others a fixed relative humidity was maintained to specifically address differences between the impact of particle treatments on ice nucleation below and above water saturation. The selected reference values used for those experiments 
were $98 \%$ and $105 \% \mathrm{RH}_{\mathrm{w}}$. These values were selected because minerals that do not have associated soluble content are expected to act as deposition-mode IN at $98 \% \mathrm{RH}_{\mathrm{w}}$, whereas $300 \mathrm{~nm}$ particles should activate as $\mathrm{CCN}$ and grow to relatively dilute cloud droplets by $105 \% \mathrm{RH}_{\mathrm{w}}$, allowing immersion/condensation-freezing to be investigated without interference from solute effects (DeMott et al., 2009; Petters et al., 2009). A particle with $D_{\text {dry }}=300 \mathrm{~nm}$ and a hygroscopicity parameter, defined by Petters and Kreidenweis (2007), of $\kappa_{\text {app }}=0.002$ (untreated ATD, determined from the CCN experiments described below) is predicted to have $s_{\mathrm{c}}=100.39 \% \mathrm{RH}_{\mathrm{w}}$, while coated particles activate at lower $\mathrm{RH}_{\mathrm{w}}$. Considering the uncertainty of $\pm 3 \%$ in the CFDC's calculated $\mathrm{RH}_{\mathrm{w}}$, all particles tested in these experiments are expected to activate as dilute cloud droplets for $\mathrm{RH}_{\mathrm{w}}>103.39 \%$. Since IN measurements at $105 \% \mathrm{RH}_{\mathrm{w}}$ will represent the combination of ice nucleation processes that occur as particles adjust to this final $\mathrm{RH}_{\mathrm{w}}$, we expect the predominance of condensation and immersion-freezing ice nucleation in activated water drops and will refer to such results as representing the immersion/condensation-freezing regime. This $\mathrm{RH}_{\mathrm{w}}$ value is also free of interference from droplets that survive the evaporation region. The $1 \mathrm{~Hz} f_{\mathrm{IN}}$ data was inherently noisy, particularly for $f_{\mathrm{IN}}<10^{-3}$, due to the overall small IN concentrations and frequent zero counts. $f_{\mathrm{IN}}$ at either reference $\mathrm{RH}_{\mathrm{w}}$ value was therefore determined by averaging all the $1 \mathrm{~Hz}$ data recorded at that value during each experiment. For $\mathrm{RH}_{\mathrm{w}}$ scans we used $f_{\mathrm{IN}}$ measured at $\mathrm{RH}_{\mathrm{w}}$ values within $\pm 0.3 \%$ of the reference $\mathrm{RH}_{\mathrm{w}}$ to characterize the ice nucleation response in either regime. 98\% $\mathrm{RH}_{\mathrm{w}}$ corresponds to $131 \% \mathrm{RH}_{\mathrm{i}}$ at $-30^{\circ} \mathrm{C}$ and to $125 \% \mathrm{RH}_{\mathrm{i}}$ at $-25^{\circ} \mathrm{C}$. $\mathrm{RH}_{\mathrm{i}}=100 \%$ occurs at $74 \% \mathrm{RH}_{\mathrm{w}}$ for $-30^{\circ} \mathrm{C}$, and at $78 \% \mathrm{RH}_{\mathrm{w}}$ for $-25^{\circ} \mathrm{C}$. Measurements of treated ATD were performed at ice chamber temperatures of $-25^{\circ} \mathrm{C}(18$ experiments) and $-30^{\circ} \mathrm{C}$ (55 experiments).

Periodic sampling of filtered, particle-free air provides a measure of the instrument's background ice counts from frost. These were typically $<2 \mathrm{~L}^{-1}$ at $75 \% \mathrm{RH}_{\mathrm{w}}$ during these experiments. Total $\mathrm{CN}$ concentrations sampled by the CFDC were typically $\sim 60-80 \mathrm{~cm}^{-3}$ but varied between 50 $150 \mathrm{~cm}^{-3}$. For the minimum $\mathrm{CN}$ of $50 \mathrm{~cm}^{-3}$ and a conservative upper limit of $5 \mathrm{~L}^{-1}$ background count, the CFDC's typical limit of quantification for these experiments was $f_{\mathrm{IN}}=\mathrm{IN} / \mathrm{CN}>10^{-4}$. For $f_{\mathrm{IN}}<10^{-4}$ we cannot distinguish these low concentrations of IN from the small background frost counts and therefore we do not ascribe any meaning to observed differences in $f_{\mathrm{IN}}$ within this low range with any confidence.

As there was not enough time during the campaign to perform enough replicate experiments to characterize the distribution and variability in populations of measured $f_{\mathrm{IN}}$ for the same treatment, it is difficult to properly determine the statistical significance of differences in $f_{\mathrm{IN}}$ measured following different treatment combinations. We did perform student $\mathrm{t}$-tests for a subset of exemplary treatments in which more than one replicate was performed, to provide a sense of what degree of difference in $f_{\mathrm{IN}}$ is necessary to conclude that different treatments produced statistically different mean values of $f_{\mathrm{IN}}$. The results of these tests are described along with the experimental results below. In our discussion, we focus on treatments that produced changes in $f_{\mathrm{IN}}$ of an order of magnitude or more, which is typically greater than the uncertainty limits and produced significantly different $f_{\text {IN }}$ values at the $99 \%$ confidence level according to the t-test. We also focus on the $-30^{\circ} \mathrm{C}$ measurements, as we were better able to detect changes in $f_{\mathrm{IN}}$ at this lower temperature and performed more measurements there.

\subsection{Estimation of sulphuric acid mass added to treated particles}

The total sulphate mass was determined following standard AMS calibration procedures (Jimenez et al., 2003). The particle sulphate mass fraction was estimated by dividing the total sulphate mass by the total particle mass. The later was estimated from the total $\mathrm{CN}$ counts measured by the CPC. As the aerosol was monodisperse, it has been assumed that all the particles of the selected size had the same surface area and thus had the same amount of sulphuric acid condensed. The uncertainty of the AMS mass loadings was estimated by the standard deviation of the average of the measured time series plus the propagated errors of the required correction factors. The sulphate particle mass fraction was above the detection limit for all treatments that included the sulphuric acid coating.

The hygroscopicity of the chemically processed particles was determined by cloud condensation nuclei $(\mathrm{CCN})$ activation experiments using the $\mathrm{CCNc}$. The $\mathrm{CCN} / \mathrm{CN}$ ratio of the size-selected aerosol was measured at increasing $\mathrm{RH}_{\mathrm{w}}$ above water saturation to produce the $\mathrm{CCN}$ activation curve (e.g. Sullivan et al., 2009b; Wex et al., 2009). The determined critical supersaturation $\left(\mathrm{s}_{\mathrm{c}}=\mathrm{RH}_{\mathrm{w}}-100\right)$ - dry diameter data pair was converted to an apparent hygroscopicity, $\kappa_{\text {app }}$ (Petters and Kreidenweis, 2007). A surface tension of pure water was assumed in all cases following Petters and Kreidenweis (2007). We assumed that any secondary material added to the dust particles during treatment, such as metal sulphate salts that may have been produced, was dissolved above water saturation. This assumption ignores the possible contribution from components with limited solubility that could reduce apparent hygroscopicity (Petters and Kreidenweis, 2008; Sullivan et al., 2009b). The $\kappa_{\text {app }}$ is related to the particle volume fraction of sulphuric acid through equation (1), following the volume mixing rule (Petters and Kreidenweis, 2007):

$\kappa_{\mathrm{app}}=\varepsilon_{\mathrm{H}_{2} \mathrm{SO}_{4}} \kappa_{\mathrm{H}_{2} \mathrm{SO}_{4}}+\varepsilon_{\mathrm{ATD}} \kappa_{\mathrm{ATD}}$

where $\varepsilon_{\mathrm{H}_{2} \mathrm{SO}_{4}}$ and $\varepsilon_{\mathrm{ATD}}$ are the volume fractions of each component, and $\kappa_{\mathrm{H}_{2} \mathrm{SO}_{4}}$ and $\kappa_{\mathrm{ATD}}$ the apparent hygroscopicities of sulphuric acid and Arizona Test Dust, respectively. 
As $\varepsilon_{\mathrm{H}_{2} \mathrm{SO}_{4}}+\varepsilon_{\mathrm{ATD}}=1$, Eq. (1) can be rearranged to derive the volume fraction of sulphuric acid from the measured $\kappa_{\mathrm{app}}$ (Sullivan et al., 2009a):

$\varepsilon_{\mathrm{H}_{2} \mathrm{SO}_{4}}=\frac{\kappa_{\mathrm{app}}-\kappa_{\mathrm{ATD}}}{\kappa_{\mathrm{H}_{2} \mathrm{SO}_{4}}-\kappa_{\mathrm{ATD}}}$

$\kappa_{\mathrm{ATD}}$ was found to be 0.002 during these experiments (Table 1 ), which is similar to the $\kappa_{\text {app }}=0.002-0.003$ reported by Herich et al. (2009). Koehler et al. (2009) reported a larger hygroscopicity for dry-generated ATD, $\kappa_{\text {app }}=0.025$. This could be due to differences between sample lots, differences in sample handling, or the fact that Koehler et al. (2009) used the A2 Fine grade of ATD while the A1 Ultrafine grade was used in this study and by Herich et al. (2009). For sulphuric acid $\kappa_{\mathrm{H}_{2} \mathrm{SO}_{4}}=0.68-0.74$ for dry diameters $30-80 \mathrm{~nm}(\kappa=0.9$ was mistakenly given in Petters and Kreidenweis, 2007 and the correct value is reported in Shantz et al., 2008); here we assume $\kappa_{\mathrm{H}_{2} \mathrm{SO}_{4}} \sim 0.7$. We did not attempt to predict the chemical form of the sulphuric acid coating. Reactions with mineral components in ATD that form sulphate salts may have occurred that have a different solubility and apparent hygroscopicity than sulphuric acid. We also assumed the same $\kappa_{\text {app }}$ for the coating when ammonia gas was used, though some fraction of the available sulphuric acid was converted to ammonium sulphate salts. $\left(\mathrm{NH}_{4}\right)_{2} \mathrm{SO}_{4}$ has $\kappa=0.61$ (Petters and Kreidenweis, 2007), slightly smaller than $\kappa_{\mathrm{H}_{2} \mathrm{SO}_{4}}=0.7$. The error in the fitted $s_{\mathrm{c}}$ was determined from the variability in the repeated instrument calibrations with ammonium sulphate aerosol, and converted to $\kappa_{\text {app }}$ to produce an upper and lower estimate range of $\varepsilon_{\mathrm{H}_{2} \mathrm{SO}_{4}}$ (Eq. 2).

\section{Results}

Figure 2 displays the fraction of particles that froze at $-30{ }^{\circ} \mathrm{C}$ during $\mathrm{RH}_{\mathrm{w}}$ scans from $75 \%$ to $>110 \%$. The untreated ATD's freezing efficiency increased monotonically with increasing $\mathrm{RH}_{\mathrm{w}}$. Below water saturation $f_{\mathrm{IN}}$ is expected to increase with $\mathrm{RH}_{\mathrm{w}}$ as higher relative humidities with respect to water and ice allow critical ice embryo formation and growth to occur at a larger fraction of ice-active surface sites which possess varying ice embryo energy barriers (Vali, 1985). At some point above water saturation, for which the particles are immersed in cloud droplets, ice nucleation at the active sites should no longer respond to changes in the gas-phase relative humidity. However, changes in IN fraction do occur until $\sim 105 \% \mathrm{RH}_{\mathrm{w}}$. Several factors may be responsible for the increase in fractional ice activation with increasing $\mathrm{RH}_{\mathrm{w}}$ above water saturation. Higher $\mathrm{RH}_{\mathrm{w}}$ set points lead to slightly earlier $\mathrm{CCN}$ activation of droplets, and larger droplets that survive longer within the CFDC evaporation region. Using the microphysical model of CFDC processes from Rogers (1988) we calculate that droplets formed following CCN activation of $300 \mathrm{~nm}$ (spherical equivalent) particles and growing at $-30^{\circ} \mathrm{C}$ with an assumed water mass accommodation

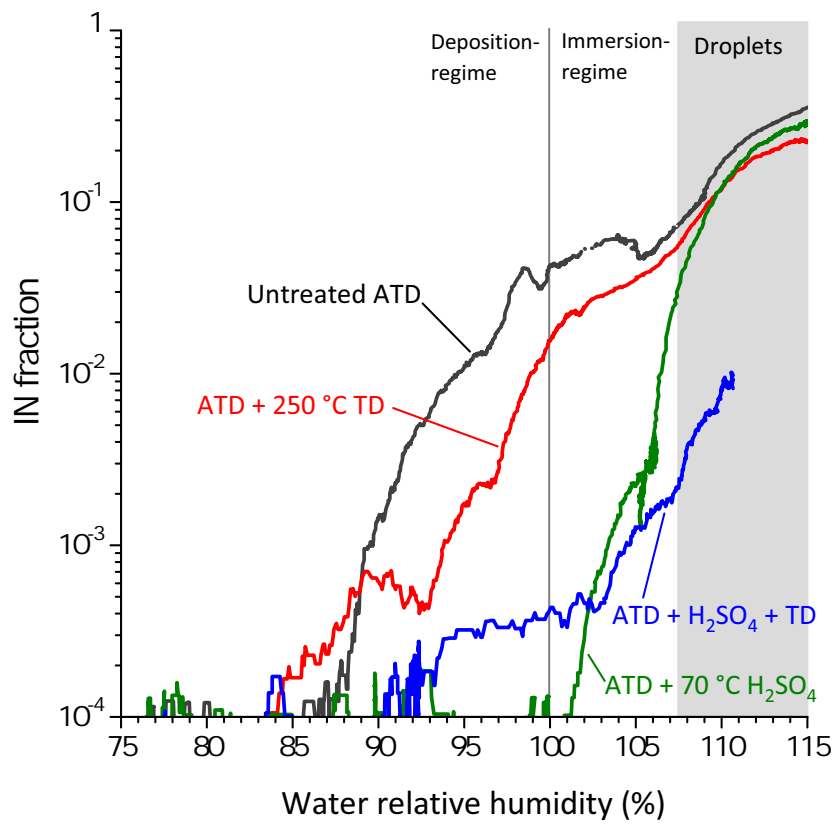

Fig. 2. Fraction of $300 \mathrm{~nm}$ ATD particles that nucleated ice at $-30^{\circ} \mathrm{C}$ as the relative humidity with respect to water was increased. Data points collected at $1 \mathrm{~Hz}$ during slow $\mathrm{RH}_{\mathrm{W}}$ scans and smoothed using a $30 \mathrm{~s}$ adjacent average. Results for untreated ATD are displayed along with those for ATD heated in the thermodenuder (TD) at $250^{\circ} \mathrm{C}$, ATD coated with sulphuric acid (SA) at $70^{\circ} \mathrm{C}$, and coated ATD subsequently heated in the TD before analysis in the CFDC. Above $\sim 107 \% \mathrm{RH}_{\mathrm{W}}$ droplets broke through the evaporation region and could not be distinguished from ice crystals (grey box).

coefficient of 1 are expected to achieve a maximum diameter of $1.7 \mu \mathrm{m}$ at a $102 \% \mathrm{RH}_{\mathrm{W}}$ set point, $2.7 \mu \mathrm{m}$ for $105 \%$ $\mathrm{RH}_{\mathrm{w}}$, and $4.0 \mu \mathrm{m}$ for $109 \% \mathrm{RH}_{\mathrm{w}}$ during residence time in the CFDC growth region. Corresponding residence times of cloud droplets in the chamber at sizes above $1 \mu \mathrm{m}$ are calculated to be 3.5, 5.1, and 5.4 s at 102, 105, and $109 \%$ $\mathrm{RH}_{\mathrm{w}}$. The role of stochastic effects on freezing of mineral dusts with highly heterogeneous surface properties remains unresolved (Connolly et al., 2009; Marcolli et al., 2007; Niedermeier et al., 2010a; Phillips et al., 2008; Vali, 2008), and the 50\% increase in residence times of particles immersed in drops for supersaturations between 102 and $109 \% \mathrm{RH}_{\mathrm{w}}$ seems unlikely as a major source of stronger activation at high $\mathrm{RH}_{\mathrm{w}}$. The up to 4 times water volume increase (for 102 vs. $105 \% \mathrm{RH}_{\mathrm{w}}$ ), could affect microscale processes involving reactions and dissolution of surface contaminants responsible for freezing point depressions prior to heterogeneous freezing. Dissolution rates and reactions appear of more likely importance since equilibrium melting point depressions are less than $0.1{ }^{\circ} \mathrm{C}$ in all cases for the solution compositions predicted on the basis of coatings applied in this study. A consequence of droplet survival into the CFDC evaporation region is an additional cooling (during $\mathrm{RH}$ reduction to ice saturation conditions) calculated to be up to $2.5^{\circ} \mathrm{C}$ for a set 
point of $105 \% \mathrm{RH}_{\mathrm{w}}$, and with sufficient time available for some percentage of those droplets nucleating ice to grow to detectable ice crystal sizes. This could be envisioned as an increased one-sided (cold) temperature uncertainty for higher RH activation conditions. It must be noted that all of these calculations were made for drops forming in the average conditions of the aerosol lamina in the CFDC. Any unexpected broadening of the aerosol particle distribution from the centre of the focused aerosol lamina would necessarily lead to a wider range of apparent activation conditions within the water supersaturated regime. While factors leading to the $\mathrm{RH}_{\mathrm{w}}$ activation signature require further study, our assumption in the present paper is that the plateau in $f_{\mathrm{IN}}$ at and above $105 \% \mathrm{RH}_{\mathrm{w}}$ characterizes the maximum value due to a combination of ice nucleation mechanisms, but with predominance of condensation/immersion freezing. Similar trends of $f_{\mathrm{IN}}$ continuing to increase above water saturation have been observed in a variety of pure mineral dust particles (Welti et al., 2009) and biomass combustion particles (DeMott et al., 2009; Petters et al., 2009).

In Fig. 2 droplets are observed to break through the evaporation region and be erroneously counted as IN at $\mathrm{RH}_{\mathrm{w}}>107 \%$. While the breakthrough point did vary between 107-112\% between different days and experiments, the sudden increase in IN that indicate droplet breakthrough are, in our instrument, never observed below $107 \% \mathrm{RH}_{\mathrm{w}}$ for dust, ambient particles, or ammonium sulphate test aerosol. Therefore the IN measurements performed at $\mathrm{RH}_{\mathrm{w}} \leq 106 \%$ should not have experienced interference from droplets. The suitability of this criterion was confirmed during the project by sampling ammonium sulphate aerosol, which does not freeze above $-38^{\circ} \mathrm{C}$; droplets broke through the evaporation region at $>113 \% \mathrm{RH}_{\mathrm{w}}$ at $-30^{\circ} \mathrm{C}$.

Also shown in Fig. 2 are results for uncoated ATD that had been heated at $250^{\circ} \mathrm{C}$ in the thermodenuder. This treatment slightly reduced the ice nucleation efficiency in the deposition nucleation regime, while freezing in the immersion/condensation-freezing regime was largely unaffected. Additional thermodenuder experiments not shown in Fig. 2 in which uncoated ATD was heated to 45, 70, 85, or $250^{\circ} \mathrm{C}$ displayed similar behaviour within the experimental uncertainties.

Coating the ATD particles with sulphuric acid (Fig. 2) greatly reduced the IN fraction below water-saturation compared to the untreated particles, while $f_{\mathrm{IN}}$ was reduced to a lesser degree above water saturation. Heating the coated ATD caused a small further reduction in $f_{\mathrm{IN}}$ in the immersion/condensation-freezing regime. Within the measurement uncertainty no further increase in $f_{\mathrm{IN}}$ was observed in Fig. 2 at $105 \% \mathrm{RH}_{\mathrm{w}}$ for the untreated and heated ATD, compared to the low $f_{\mathrm{IN}}$ for coated and coated + heated ATD at $105 \% \mathrm{RH}_{\mathrm{w}}$. This plateau indicates that this region is sensitive to changes in the immersion/condensation-freezing regime's behaviour. ATD coated with SA (with or without subsequent heating) also displayed a brief plateau in $f_{\text {IN }}$ near
$105 \% \mathrm{RH}_{\mathrm{w}}$, followed by a sharp rise in $f_{\mathrm{IN}}$ as $\mathrm{RH}_{\mathrm{w}}$ was increased further. This sharp increase in $f_{\mathrm{IN}}$ at these high $\mathrm{RH}_{\mathrm{w}}$ conditions is consistent with the appearance of water droplets grown to sizes that survive through the evaporation region of the CFDC and interfere with the optical counting of IN grown as ice crystals (Petters et al., 2009). The onset of this behaviour at approximately $107 \% \mathrm{RH}_{\mathrm{w}}$ at $-30^{\circ} \mathrm{C}$ for this CFDC configuration and flow rate used in this study is quantitatively consistent with the conditions for water droplets at sizes $>2 \mu \mathrm{m}$ to survive to the OPC based on calculations using a simple model of particle growth in the CFDC (Rogers, 1988). We therefore conclude that the increase in $f_{\text {IN }}$ above $106 \% \mathrm{RH}_{\mathrm{w}}$ was due to droplet breakthrough, and not the sudden onset of immersion/condensation-freezing under high $\mathrm{RH}_{\mathrm{w}}$ conditions.

\subsection{Relationship between freezing ability and amount of soluble material added}

The IN fractions for the $-30^{\circ} \mathrm{C}$ immersion/condensation freezing regime data from SA coating and SA coating + water bath + ammonia are plotted in Fig. $3 a$ as a function of the particle volume fraction of sulphuric acid, as estimated from the CCN measurements (Eq. 2), and in Fig. 3b as a function of the sulphate particle mass fraction estimated from the AMS measurements. Using either estimate of the amount of soluble material added to the dust particles produces a trend of decreasing $f_{\mathrm{IN}}$ with increasing sulphuric acid particle mass/volume fraction. In Fig. 3a $f_{\mathrm{IN}}$ is not as low as expected following this trend for the $85^{\circ} \mathrm{C}$ coating. This may indicate that increasing the amount of sulphuric acid condensed has a limited effect on ice nucleation above a certain threshold, or be due to increased uncertainty in the volume fraction of sulphuric acid when particle hygroscopicity is high (note the larger error bar). When the coated particles were also passed over the water bath and exposed to additional ammonia gas a larger decrease in $f_{\mathrm{IN}}$ was achieved for a similar amount of sulphate per particle deposited according to the AMS measurements. We do not include data from other treatment combinations such as the use of heat following the coating as these lie well off the trends in Fig. 3 and likely represent different physicochemical processes, as discussed below; heat decreased $f_{\mathrm{IN}}$ while also reducing the amount of sulphate.

\subsection{Freezing efficiency of sulphuric acid coated mineral dust}

The freezing efficiencies of ATD after various treatments in both the deposition and immersion/condensation-freezing regimes are compared in Fig. 4 for $-30^{\circ} \mathrm{C}$ and Fig. 5 for $-25^{\circ} \mathrm{C}$. The treatments include (1) heating in the thermodenuder (TD), (2) sulphuric acid (SA) coating, (3) $\mathrm{SA}+\mathrm{TD}$, (4) $\mathrm{SA}+$ passage over the water bath $(\mathrm{WB})+\mathrm{NH}_{3}$ 
gas exposure, (5) $\mathrm{SA}+\mathrm{WB}+\mathrm{NH}_{3}+\mathrm{TD}$, (6) $\mathrm{SA}+\mathrm{NH}_{3}$, (7) $\mathrm{NH}_{3}$ exposure only. The average estimated sulphate mass per particle from the AMS is also shown for each treatment combination. Ice nucleation in the deposition regime was significantly more sensitive to all treatments compared to immersion/condensation-freezing; $f_{\mathrm{IN}}$ in the deposition regime was reduced by about one order of magnitude more after coating compared to the reduction in the immersion/condensation regime after coating. Measurements of $f_{\mathrm{IN}}$ at both -30 and $-25^{\circ} \mathrm{C}$ responded similarly to all the various physicochemical processing combinations described below; however the effect of treatments on $f_{\mathrm{IN}}$ at $-25^{\circ} \mathrm{C}$ and $98 \% \mathrm{RH}_{\mathrm{w}}$ was difficult to assess due to the small $f_{\mathrm{IN}}$ values, only modestly exceeding quantification limits in some cases, for both treated and untreated ATD.

The sulphuric acid (SA) coating experiments are the reference treatment to which further treatment combinations are compared below, and thus we first describe the effects of this treatment. Coating with sulphuric acid at 70 or $85^{\circ} \mathrm{C}$ caused large decreases in $f_{\mathrm{IN}}$ of at least one order of magnitude both below and above water saturation. Particles coated with sulphuric acid at $45^{\circ} \mathrm{C}$ displayed a large decrease in $f_{\mathrm{IN}}$ below water saturation, but their immersion/condensation regime freezing efficiency was only slightly smaller and within experimental uncertainties compared to untreated or heated-only ATD. These were the only experiments in which the addition of sulphuric acid did not cause immersion/condensation-freezing $f_{\mathrm{IN}}$ to decrease below $10^{-2}$ at the selected temperatures. The amount of sulphuric acid condensed on the particles at $45^{\circ} \mathrm{C}$ was $\sim 42 \%$ of that added by the $70^{\circ} \mathrm{C}$ coatings (AMS measurements, Table 1) and corresponds to an approximately $1.0 \mathrm{~nm}$ uniform particle coating assuming a $300 \mathrm{~nm}$ spherical physical diameter dust core. The thickness of one monolayer equivalent of pure sulphuric acid is estimated to be $0.55 \mathrm{~nm}$, based on its molar volume, corresponding to $287 \mathrm{ag} / \mathrm{particle}$ of sulphate. The sulphate mass from the $70^{\circ} \mathrm{C}$ coating temperature corresponds to a $2.4 \mathrm{~nm}$ thickness, and the $85^{\circ} \mathrm{C}$ coating corresponds to a $4.1 \mathrm{~nm}$ thick uniform coating. Therefore, for all coating temperatures we estimate that enough sulphate mass was condensed to potentially produce at least one complete monolayer coverage. No measurements of the coated particle morphologies were available and the estimates of monolayer coverage are not intended to suggest that the sulphuric acid coated the ATD particles uniformly, even when enough sulphate mass to produce a complete monolayer was present.

While heating uncoated ATD at $250^{\circ} \mathrm{C}$ in the TD caused just a small decrease in $f_{\text {IN }}$ within the uncertainty limits, the addition of sulphuric acid at 70 or $85^{\circ} \mathrm{C}$ plus heating in the thermodenuder reduced deposition regime ice nucleation efficiency below the CFDC's quantification limit $\left(f_{\mathrm{IN}}<10^{-4}\right)$. Immersion/condensation-freezing was less sensitive to the thermochemical processing causing $f_{\mathrm{IN}}$ to be $>10^{-4}$ after SA coating, and thus allowing differences in the IN fraction to be discerned under the various treatment conditions. Coat-
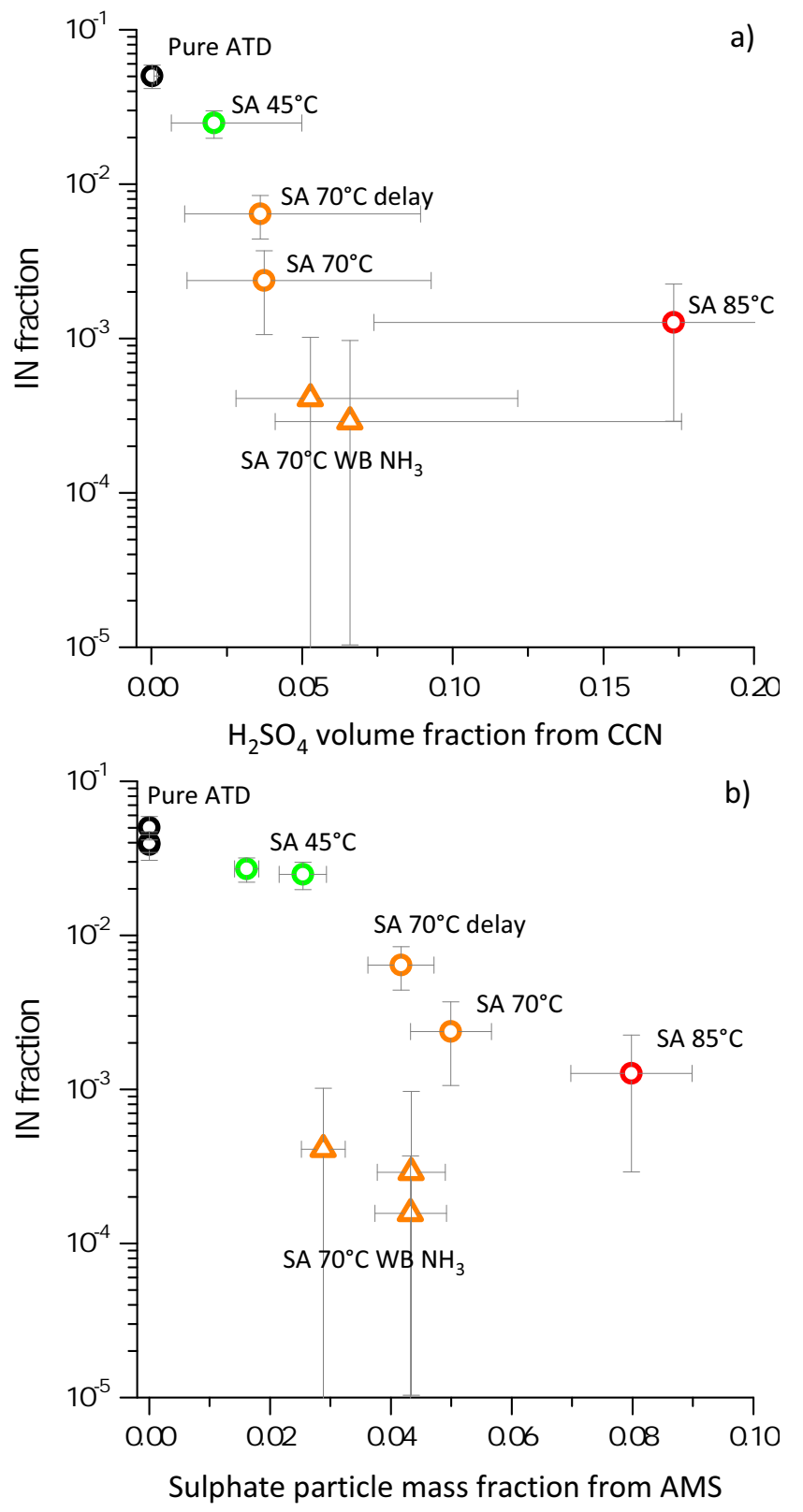

Fig. 3. Fraction of $300 \mathrm{~nm}$ ATD particles that nucleated ice at $-30{ }^{\circ} \mathrm{C}$ and $\mathrm{RH}_{\mathrm{W}}=105 \%$ (condensation/immersion-regime) after different treatment combinations, plotted versus (a) the particle's sulphuric acid volume fraction estimated from the CCN hygroscopicity measurements, or (b) the sulphate particle mass fraction estimated from the AMS measurements. Delay refers to experiments performed with an additional volume in the flow path to increase the treatment time.

ing with sulphuric acid at $45^{\circ} \mathrm{C}$ followed by heating caused a one order of magnitude reduction in $f_{\mathrm{IN}}$ at $105 \% \mathrm{RH}_{\mathrm{w}}$ compared to the reference treatment. The higher SA coating temperatures of 70 and $85^{\circ} \mathrm{C}$ decreased $f_{\mathrm{IN}}$ further at $105 \%$ $\mathrm{RH}_{\mathrm{w}}$ after the thermodenuder. 
In general, ice nucleation in the deposition and immersion/condensation-freezing regimes responded to thermochemical processing in the same manner at $-25^{\circ} \mathrm{C}$ as for $-30^{\circ} \mathrm{C}$. $f_{\mathrm{IN}}$ were overall smaller at $-25^{\circ} \mathrm{C}$, as expected given the exponential dependence of $f_{\mathrm{IN}}$ on temperature (Vali, 1985) that has been observed in mineral particle systems (e.g. Archuleta et al., 2005; Welti et al., 2009). ATD coated at 45 and $70^{\circ} \mathrm{C}$ and then heated had a $f_{\mathrm{IN}}$ at $98 \% \mathrm{RH}_{\mathrm{w}}$ and $-25^{\circ} \mathrm{C}$ similar to uncoated ATD. This is the only qualitative difference compared to the measurements at $-30^{\circ} \mathrm{C}$, where coated then heated particles always had a much reduced $f_{\mathrm{IN}}$ at $98 \% \mathrm{RH}_{\mathrm{w}}$; the overall low $f_{\mathrm{IN}}$ values $\left(<10^{-3}\right)$ measured for both uncoated and coated dust at $-25^{\circ} \mathrm{C}$ make it difficult to distinguish between the two under these conditions. Above water saturation coated then heated ATD had a reduced $f_{\mathrm{IN}}$ at $105 \% \mathrm{RH}_{\mathrm{w}}$ compared to untreated or coatedonly particles at both -25 and $-30{ }^{\circ} \mathrm{C}$.

The student's t-test was used to evaluate the statistical significance in differences of $f_{\mathrm{IN}}$ values for various thermochemical treatments. This test was used to compare pooled $f_{\text {IN }}$ values for exemplary treatment combinations only when more than one replicate was performed, and not assuming equal variance between the two treatment populations. As a guide to the degree of change in $f_{\mathrm{IN}}$ required to produce significantly different $f_{\mathrm{IN}}$ values, at $-30{ }^{\circ} \mathrm{C}$ and $105 \% \mathrm{RH}_{\mathrm{w}}$, untreated vs. heated ATD (TD) was significantly different at the $94 \%$ confidence level, unheated ATD vs. SA 45 was different at the 97\% confidence level, and both unheated ATD vs. SA $45 \mathrm{TD}$ and unheated ATD vs. SA 70 were different at the $99 \%$ confidence level. The latter two comparisons where the results were significantly different at a high confidence level had differences in $f_{\mathrm{IN}}$ greater than one order of magnitude. We therefore use a one order of magnitude difference in $f_{\mathrm{IN}}$ as a benchmark to determine if treatments produced statistically different results, particularly when only one replicate was performed.

The single-particle measurements obtained by the ATOFMS were queried for various experiments representative of the most common experimental treatment combinations reported here. Using a conservative sulphate peak area threshold of $>1000$, between 84 and $97 \%$ of ATD particles contained sulphate for experiments in which ATD particles passed through the sulphuric acid coating tube (and in some cases additional treatments following this). Using a less conservative peak detection limit (peak height $>50$ above baseline) decreases the maximum number fraction of particles that did not produce a sulphate ion signal to approximately $6 \%$. The small fraction of particles that did not produce a sulphate ion signal $>1000$ peak area indicates that these particles had no or only small amounts of sulphate, or that the ATOFMS's laser ablated a portion of the particle that did not contain sulphate, even though sulphate was added to the particle (Cziczo et al., 2009). The lack of a step-function in the shape of the $\mathrm{CCN}$ activation curve is further evidence against a substantial fraction of externally

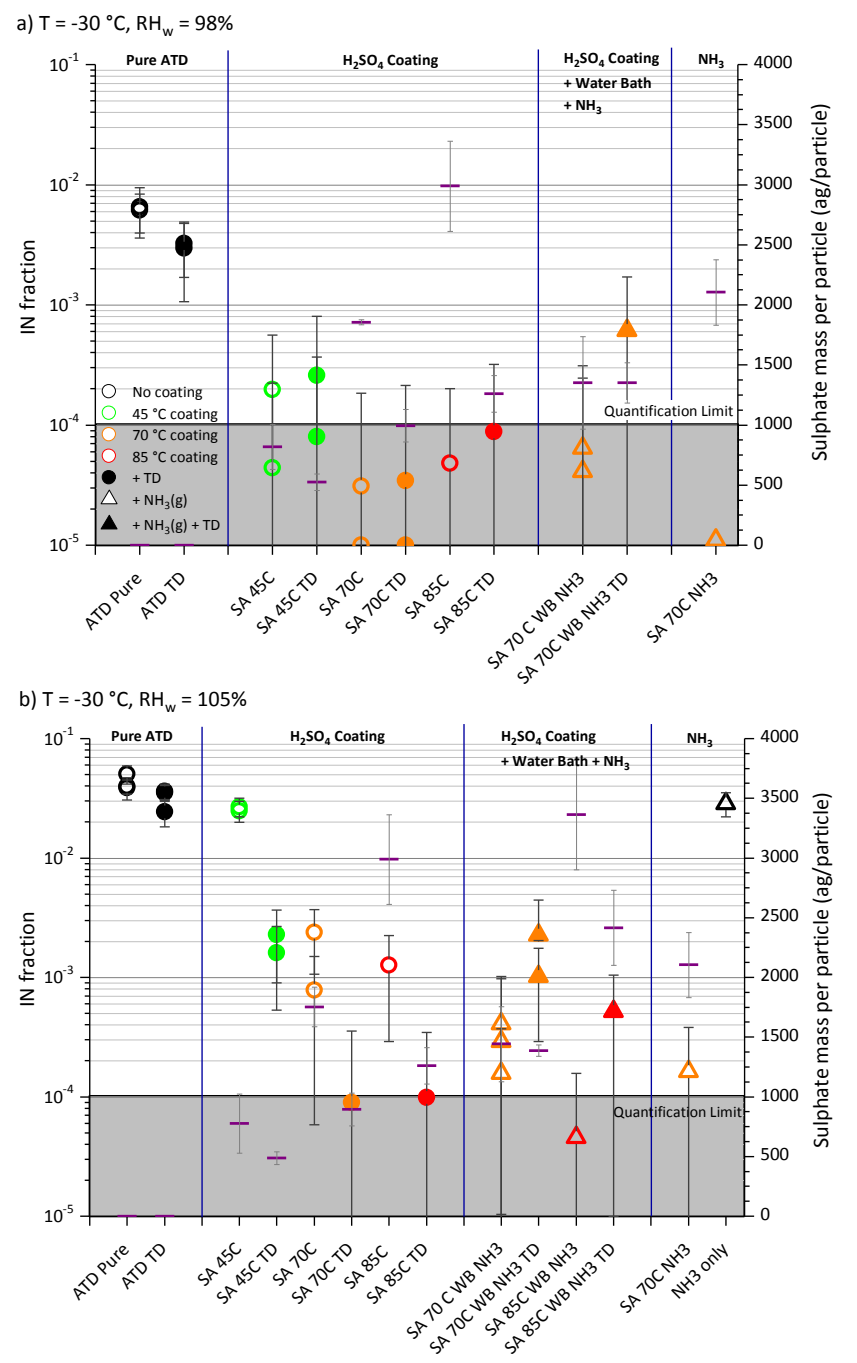

Fig. 4. Fraction of $300 \mathrm{~nm}$ ATD particles that nucleated ice after various chemical treatment combinations at $-30^{\circ} \mathrm{C}$ under (a) deposition-regime $\left(\mathrm{RH}_{\mathrm{W}}=98 \%\right)$ or (b) immersion-regime $\left(\mathrm{RH}_{\mathrm{W}}=105 \%\right)$ ice nucleation conditions. The shaded region of $f_{\mathrm{IN}}<10^{-4}$ represents the CFDC's limit of quantification for these experiments due to background frost counts; no meaning should be ascribed to differences in observed $f_{\mathrm{IN}}$ within this region. The average sulphate mass per particle estimated from the AMS is plotted (horizontal line) for each treatment. The error bar corresponds to the standard deviation in $f_{\mathrm{IN}}$ between replicates, or the standard deviation of the $1 \mathrm{~Hz} f_{\mathrm{IN}}$ data when only one replicate was performed. Thermodenuder (TD) temperature was $250^{\circ} \mathrm{C}$ in all cases. SA: sulphuric acid, WB: water bath.

mixed ATD particles that did not contain sulphuric acid. Finally, SA + TD treated particles had $f_{\mathrm{IN}}$ reduced by at least an order of magnitude compared to uncoated ATD (excluding the less reliable measurements at $-25^{\circ} \mathrm{C}$ and $98 \% \mathrm{RH}_{\mathrm{w}}$ ). As we observed that only particles exposed to sulphuric acid before heating had impaired ice nucleation 
ability following the thermodenuder, we conclude that the decrease in $f_{\mathrm{IN}}$ indicates that ATD particles that did not contain sulphuric acid could only have composed a small fraction no greater than a few percent of the total particle number.

\subsection{Effect of exposing sulphuric acid coated dust to ammonia gas}

Exposure to ammonia gas after coating with sulphuric acid reduced $f_{\mathrm{IN}}$ above water-saturation by about a factor of 10 more than the sulphuric acid coating alone did. $f_{\mathrm{IN}}$ below water-saturation was already below our limit of quantification after SA coating so we could not determine if $\mathrm{NH}_{3}$ exposure had additional effects on deposition nucleation. In most ammonia exposure experiments, the water bath was used after the SA coating and before exposure to ammonia gas. We did not observe different ice nucleation response for $\mathrm{SA}+\mathrm{WB}$ versus $\mathrm{SA}+\mathrm{WB}+\mathrm{NH}_{3}$ treatments. As we suspect the water bath branch was contaminated with ammonia, we cannot conclude whether exposure to water vapour had the same effect as $\mathrm{NH}_{3}$ exposure, or if there was sufficient $\mathrm{NH}_{3}$ in the water bath to produce the same result. Therefore, we do not present the SA + WB results and focus on the $\mathrm{SA}+\mathrm{WB}+\mathrm{NH}_{3}$ experiments.

Heating the particles following $\mathrm{NH}_{3}$ exposure $\left(\mathrm{SA}+\mathrm{WB}+\mathrm{NH}_{3}+\mathrm{TD}\right)$ had the interesting effect of increasing $f_{\mathrm{IN}}$ relative to the $\mathrm{SA}+\mathrm{WB}+\mathrm{NH}_{3}$ treatment. This partial restoration of freezing ability was more pronounced in the immersion/condensation-freezing regime, but still produced less than a factor of 10 increase in $f_{\mathrm{IN}}$. After both treatments, with or without the TD, $f_{\mathrm{IN}}$ following $\mathrm{NH}_{3}$ exposure was lower than untreated ATD. The $f_{\mathrm{IN}}$ values of $\mathrm{SA}+\mathrm{WB}+\mathrm{NH}_{3}$ vs. $\mathrm{SA}+\mathrm{WB}+\mathrm{NH}_{3}+\mathrm{TD}$ (at $-30{ }^{\circ} \mathrm{C}$ and $105 \% \mathrm{RH}_{\mathrm{w}}$ ) were not significantly different at the $90 \%$ confidence level according to the t-test. However, both treatments were significantly different compared to untreated ATD at the $99 \%$ confidence level. The mass of sulphate per particle did not decrease after heating in the thermodenuder for the $70^{\circ} \mathrm{C} \mathrm{SA}+\mathrm{WB}+\mathrm{NH}_{3}$ experiments, but was decreased with the thicker $85^{\circ} \mathrm{C}$ SA coating. Not including the water bath did not alter the poor deposition nucleation or immersion/condensation-freezing ability of dust following treatment with $\mathrm{SA}+\mathrm{NH}_{3}$. A set of experiments in which the concentration of ammonia gas was reduced by up to a factor of five did not produce a change in $f_{\mathrm{IN}}$. Uncoated ATD particles exposed only to ammonia gas displayed similar immersion/condensation-regime freezing ability as untreated dust (Fig. 4b).

\subsection{Summary of observed ice nucleation behaviour}

From the observed ice nucleation response to the wide variety of treatment conditions explored in the experiments described above, we derive the following conclusions with high
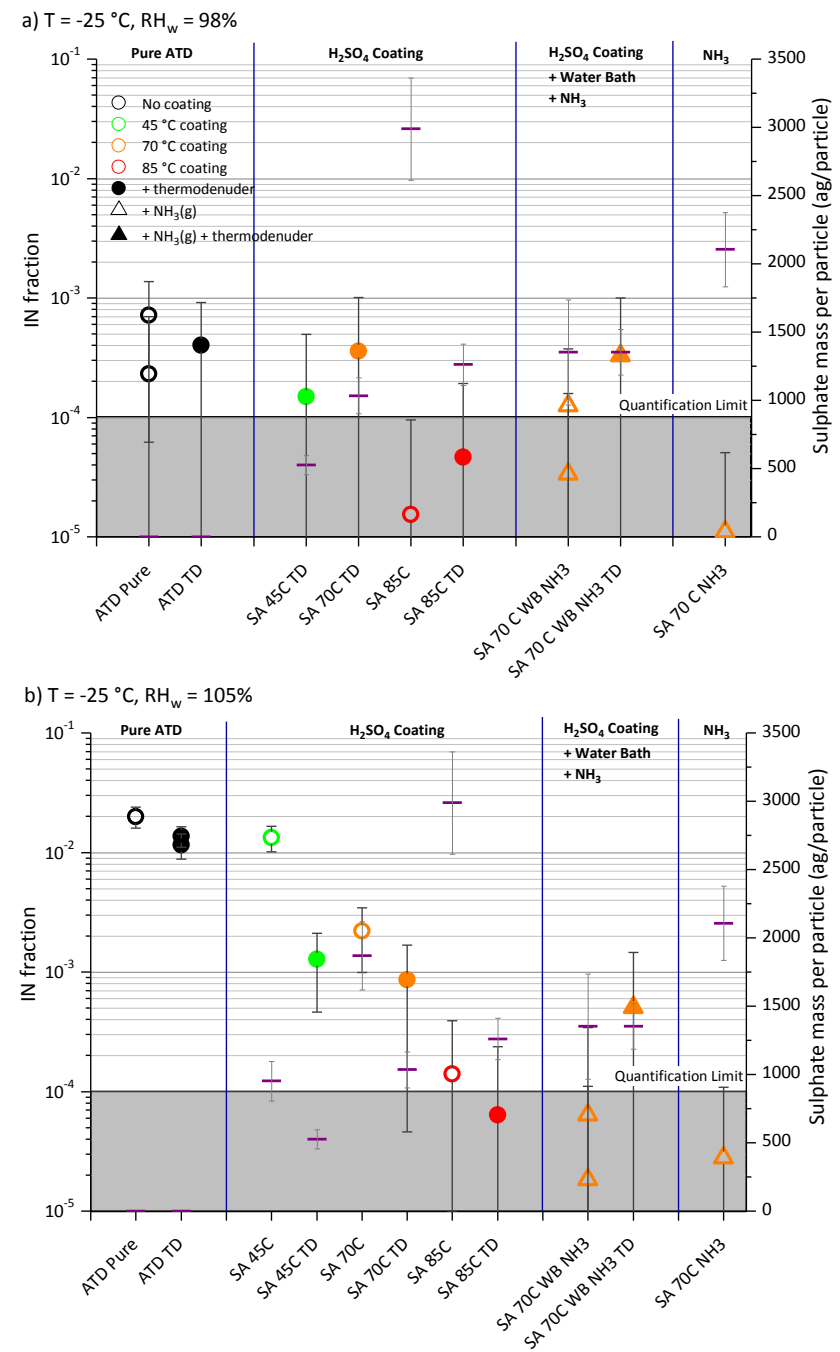

Fig. 5. Fraction of $300 \mathrm{~nm}$ ATD particles that nucleated ice at $-25^{\circ} \mathrm{C}$, as in Fig. 4.

confidence - based on the number of replicate experiments performed and the observed uncertainty in the IN fractions - in the water subsaturated deposition regime $\left(98 \% \mathrm{RH}_{\mathrm{w}}\right)$, and water supersaturated immersion/condensation-freezing regime $\left(105 \% \mathrm{RH}_{\mathrm{w}}\right)$ :

1. Heating uncoated dust did not alter ice nucleation in either regime.

2. Sulphuric acid coated dust particles always had reduced $f_{\text {IN }}$ compared to uncoated dust, except for the $45^{\circ} \mathrm{C}$ coating in the immersion/condensation-freezing regime.

3. The coating reduced $f_{\mathrm{IN}}$ by about one order of magnitude more in the deposition vs. immersion/condensation-freezing regime, compared to uncoated dust. 
4. Heating coated dust reduced $f_{\mathrm{IN}}$ further in the immersion/condensation-freezing regime. At $-25^{\circ} \mathrm{C}$ this was only observed for the $45^{\circ} \mathrm{C} \mathrm{SA}$ coating. $f_{\mathrm{IN}}$ was already below the limit of quantification in the deposition regime after coating.

5. Exposing SA treated particles to water vapour and ammonia gas reduced $f_{\mathrm{IN}}$ more than the SA coating alone, in the immersion/condensation-freezing regime.

6. Heating $\mathrm{SA}+\mathrm{WB}+\mathrm{NH}_{3}$ treated particles increased $f_{\mathrm{IN}}$ compared to the same treatment without heat, in both regimes. $f_{\mathrm{IN}}$ was still much lower than for untreated ATD.

7. No treatment combination increased $f_{\mathrm{IN}}$ above that of untreated dust.

The treatment condition, IN fraction $\left(f_{\mathrm{IN}}\right)$ at $98 \%$ (deposition regime) and $105 \% \mathrm{RH}_{\mathrm{w}}$ (immersion/condensationfreezing regime), and the standard deviation from the $1 \mathrm{~Hz}$ $f_{\mathrm{IN}}$ measurements are listed in Table 1 for the -30 and $-25^{\circ} \mathrm{C}$ experiments. Also included are the critical supersaturation $\left(s_{\mathrm{c}}\right)$, hygroscopicity parameter $\left(\kappa_{\mathrm{app}}\right)$, estimate of the sulphate volume fraction from the $\mathrm{CCN}$ measurements, and the estimated sulphate mass per particle from the AMS measurements $\left(1 \mathrm{ag}=10^{-18} \mathrm{~g}\right)$, when available.

\section{Discussion}

We interpret our experimental observations of thermochemical treatments on the ice nucleation properties of mineral dust particles under the framework that heterogeneous ice nucleation begins with the formation of a critical ice embryo at a specific ice-active surface site. According to the singular hypothesis there is a heterogeneous distribution of surface site ice nucleation energy barriers within and between individual particles, even those of the same physical size (Marcolli et al., 2007; Martin, 2000; Phillips et al., 2008; Vali, 1994, 2008). Any particle exposed to its critical temperature and $\mathrm{RH}_{\mathrm{i}}$ instantaneously freezes, with no further ice nucleation after that point. This nucleation event is determined by the active site with the lowest nucleation barrier (i.e. highest critical temperature) on each particle. Chemical or physical modification of these ice active surface sites can alter the critical temperature and $\mathrm{RH}_{\mathrm{i}}$ at which they nucleate ice, which is experimentally observed in this work by changes in the measured $f_{\mathrm{IN}}$.

In all but one experiment the addition of sulphuric acid to Arizona Test Dust particles reduced their ability to nucleate ice compared to uncoated dust, both below and above water saturation, at -30 and $-25^{\circ} \mathrm{C}$. Further, the treated dust particles' ice nucleation ability decreased as the mass of sulphuric acid added increased. We interpret this effect as a concealing or physicochemical modification of increasing fractions of the ice active sites by the condensation of sulphuric acid. Since some freezing ability remained after the lower temperature coatings, this implies that either some particles did not contain sulphuric acid, which is not supported by our suite of observations, that the particle was not completely coated at the lower coating temperatures, or that the coating was not thick enough to conceal and/or chemically alter all active sites in each particle. The $45^{\circ} \mathrm{C}$ coating condensed on average an amount of sulphuric acid greater than that estimated to form complete monolayer coverage around the particle. This treatment was observed to decrease $f_{\text {IN }}$ below-water saturation, while $f_{\text {IN }}$ above water-saturation was only slightly smaller than uncoated dust and within the uncertainty limits. Garland et al. (2008) observed oleic acid to condense on to silica mineral particles in the form of islands, as opposed to forming a uniform coating. The islands grew in height as more oleic acid was condensed, while gaps between the islands with bare silica surface remained. Cziczo et al. (2009) also obtained indirect evidence from singleparticle mass spectrometry for incompletely coated ATD particles after exposure to hot sulphuric acid vapour. If similar structures formed when sulphuric acid was condensed on to the ATD particles in our experiments, a portion of the mineral surface would have remained uncoated with unaltered ice active sites.

The addition of soluble hygroscopic sulphuric acid would have caused the coated particles to absorb water under the high $\mathrm{RH}_{\mathrm{w}} \geq 98 \%$ conditions in the CFDC. The presence of concentrated salt solutions on the particle below water saturation may have shifted the ice nucleation mechanism to an immersion/condensation-freezing-like, as opposed to deposition ice nucleation mechanism that occurs on a bare particle surface. At $98 \% \mathrm{RH}_{\mathrm{w}}$ the coating would have been more concentrated than after droplet activation at $105 \% \mathrm{RH}_{\mathrm{w}}$. This could allow solute effects to cause a freezing point depression that potentially suppresses ice nucleation that proceeds by a condensation-freezing process below water-saturation. Dissolution of a portion of the sulphuric acid coating that reveals concealed active sites when the particle is activated into a droplet above water saturation may explain the lower sensitivity of $f_{\mathrm{IN}}$ to the coatings at $105 \% \mathrm{RH}_{\mathrm{w}}$ versus $98 \% \mathrm{RH}_{\mathrm{w}}$. The fact that $f_{\mathrm{IN}}$ at $105 \% \mathrm{RH}_{\mathrm{w}}$ was still reduced by the coatings clearly indicates that dissolution during droplet activation did not completely reverse the detrimental effects caused by the sulphuric acid coating. Therefore, some fraction of the ice active sites was irreversibly lost when the sulphuric acid was condensed on the mineral particles. ATD particles exposed to nitric acid vapour at room temperature were recently observed to have reduced deposition ice nucleation ability, but unaltered immersion/condensation-freezing at the same $\mathrm{RH}_{\mathrm{w}}$ values and measured by the same CFDC used here (Sullivan et al., 2010). This suggests that there was enough time in the CFDC for soluble nitric acid coatings to be removed from surface sites by dissolution following the absorption of water above water saturation, thus restoring their ice nucleation ability. The fact that $f_{\mathrm{IN}}$ was reduced at $105 \% \mathrm{RH}_{\mathrm{w}}$ 
by the sulphuric acid coating in these experiments indicates irreversible modification of surface sites by the coating that is not reversed by dissolution.

Coated particles then exposed to heat in the thermodenuder had further reduced ice nucleation ability, even though $\sim 50-60 \%$ of the sulphate mass was removed by heating. We propose that the combination of concentrated acid plus heat accelerated chemical reactions between sulphuric acid and the mineral surface, causing a further irreversible loss of ice active sites that were not recovered by the reduction of sulphate mass. As temperatures between 45 and $85^{\circ} \mathrm{C}$ were used to condense the sulphuric acid coating, similar thermal effects may have been unintentionally induced by the hot coating oven itself. Thus, the relative contributions of sulphuric acid and heat to the observed decrease in ice nucleation ability cannot be clearly separated, although heating uncoated particles did not decrease $f_{\mathrm{IN}}$ significantly. Whether the lack of a decrease in $f_{\mathrm{IN}}$ at $105 \% \mathrm{RH}_{\mathrm{w}}$ for the $45^{\circ} \mathrm{C}$ SA coating was caused by the smaller amount of sulphuric acid condensed, by the lower oven temperature used, or by a combination of the two cannot be determined.

Exposing coated particles to ammonia gas was intended to convert most or all of the sulphuric acid to ammonium sulphate salts. The $\mathrm{SA}+\mathrm{WB}+\mathrm{NH}_{3}$ treatment reduced condensation/immersion-freezing ability even further, compared to SA coating only. The same effect was achieved when the water bath was not used in-between the SA and $\mathrm{NH}_{3}$ exposures. Heating the $\mathrm{SA}+\mathrm{WB}+\mathrm{NH}_{3}$ particles produced a partial recovery of $f_{\mathrm{IN}}$ at $105 \% \mathrm{RH}_{\mathrm{w}}$ and $<5 \%$ loss of sulphate mass. Converting the sulphuric acid coating to ammonium sulphate appears to have impaired ice nucleation even more than the sulphuric acid coating alone did, even though the mass of sulphate per particle was on average 19\% lower following ammonia exposure. Absorption of water by the sulphuric acid coating in the water bath prior to $\mathrm{NH}_{3}$ exposure may have caused the island structures proposed above to swell and more evenly coat the entire particle surface. This would allow the acid to conceal and/or react with a larger fraction of the active sites. However, particles exposed to ammonia following the sulphuric acid coating but without exposure to humid air in the water bath $\left(\mathrm{SA}+\mathrm{NH}_{3}\right)$ had similarly low $f_{\mathrm{IN}}$ as when the water bath was used. We would expect neutralization of sulphuric acid by ammonia uptake to reduce the irreversible loss of active sites normally caused by reaction with sulphuric acid. Thus, the further reduction of $f_{\mathrm{IN}}$ following ammonia exposure is counter-intuitive and warrants further investigation.

Large solid ammonium sulphate particles have been observed to heterogeneously nucleate ice at temperatures lower than about $-40^{\circ} \mathrm{C}$ (Abbatt et al., 2006). Therefore, mineral dust coated with ammonium sulphate might be more efficient ice nuclei compared to sulphuric acid coated particles; we did not observe this behaviour at -30 or $-25^{\circ} \mathrm{C}$, above or below water saturation. Our results are similar to the observations of Eastwood et al. (2009) at $-28^{\circ} \mathrm{C}$ in the deposition-regime, for mineral particles coated by deliquesced ammonium sulphate, or sulphuric acid. Here we observed that ammonium sulphate coated ATD had even lower ice nucleation ability than SA coated dust in the condensation/immersion-freezing regime. Cziczo et al. (2009) found similarly poor ice nucleation ability for sulphuric acid coated ATD and coated ATD exposed to ammonia gas, at $-35^{\circ} \mathrm{C}$.

When the coated, humidified, and ammonia exposed particles were heated, some ice nucleation ability was restored at $105 \% \mathrm{RH}_{\mathrm{w}}$, compared to the unheated $\mathrm{SA}+\mathrm{WB}+\mathrm{NH}_{3}$ treatment. A small recovery in $f_{\mathrm{IN}}$ at $98 \% \mathrm{RH}_{\mathrm{w}}$, within the uncertainty limits, was also observed. However, the mass of sulphate per particle was only reduced by $\sim 4 \%$ on average after the thermodenuder for the $70^{\circ} \mathrm{C} \mathrm{SA}$ coating. Conversely, coated particles that were heated without passing over the water bath or exposure to ammonia had reduced $f_{\mathrm{IN}}$ while losing $\sim 50 \%$ of the sulphate mass. Neutralization of sulphuric acid by the uptake of ammonia gas and/or dilution of the acidic coating by water absorption in the water bath may have impeded the additional irreversible loss of surface sites via chemical reactions when the coated particles were heated. Some active sites could then have been revealed when the small portion of sulphate mass was removed by heating. Alternatively, the absorption of water vapour by the sulphuric acid coated dust may have accelerated chemical reactions between the acid and various minerals present in ATD, and/or facilitated previously inaccessible reaction pathways requiring water (Lasaga, 1995). The production of low volatility products from the combination of dilute sulphuric acid plus heat would explain the small fraction of sulphate mass removed. If these products were insoluble and produced new ice active sites, or if additional active sites were uncovered when the initial surface was digested by these chemical reactions, that could account for the observed partial recovering of ice nucleation ability at $105 \% \mathrm{RH}_{\mathrm{w}}$. We were unable to identify the products from these proposed chemical reactions. ATD is approximately composed by mass of $5 \% \mathrm{CaCO}_{3}, 5 \% \mathrm{MgCa}\left(\mathrm{CO}_{3}\right)_{2}$, and $5 \% \mathrm{Fe}$ compounds, with the remainder as aluminosilicate minerals (Vlasenko et al., 2005). Possible reaction products include $\mathrm{CaSO}_{4}, \mathrm{MgSO}_{4}$, $\mathrm{FeSO}_{4}, \mathrm{Fe}_{2}\left(\mathrm{SO}_{4}\right)_{3}$, their hydrates, and products from the reaction of sulphuric acid with aluminosilicates. Archuleta et al. (2005) found that pure $\mathrm{Fe}_{2} \mathrm{O}_{3}$ particles became more efficient IN when coated by sulphuric acid at $200^{\circ} \mathrm{C}$. $\mathrm{CaSO}_{4}$ and $\mathrm{MgSO}_{4}$ are insoluble, while the two iron sulphate salts will dissolve at typical water contents of haze particles. The anhydrous forms of all four compounds have decomposition or melting temperatures of $400^{\circ} \mathrm{C}$ or higher. The thermodenuder was typically operated at $250^{\circ} \mathrm{C}$.

\subsection{Comparison to previous studies and atmospheric implications}

Previous investigations, although difficult to compare to quantitatively due to differences in experimental methods, 
have reported a similar decrease in heterogeneous ice nucleation ability by coating various mineral particles types with sulphuric acid (Archuleta et al., 2005; Cziczo et al., 2009; Eastwood et al., 2008; Niedermeier et al., 2010a). We note that Niedermeier et al. (2010a) only observed a decrease in $f_{\mathrm{IN}}$ at the highest temperature they explored, $-34^{\circ} \mathrm{C}$. During FROST-2 LACIS was operated at up to $-28^{\circ} \mathrm{C}$ and observed a decrease in $f_{\text {IN }}$ for SA coated ATD particles similar to that reported here using the CFDC (Niedermeier et al., 2010b). The observations reported here and by these previous studies clearly indicate a reduction in ice nucleation ability when sulphuric acid is added to mineral dust particles - with the caveat that the contribution to this reduction caused by the heat used in the coating process is not known. Knopf and Koop (2006) reported a similarly large range of onset $\mathrm{RH}_{\mathrm{i}}$ for ATD particles atomized from a dilute sulphuric acid solution and for atomized ATD and concluded that uncoated and sulphuric acid coated ATD had no significant difference in ice nucleation ability. Similarly, Zobrist et al. (2008) found that ATD particles immersed in dilute sulphuric acid droplets displayed only a freezing point depression for immersion/condensation-freezing, that was attributed to the solution's decreased water activity, and inferred no alteration of active sites by the acid. At $105 \%$ $\mathrm{RH}_{\mathrm{w}}$ any solute present would be very dilute, and thus our observed reduction in $f_{\mathrm{IN}}$ caused by sulphuric acid condensation cannot be explained by solute effects. The different results obtained in this and the previously cited studies could be explained by differences in the particle generation and coating methods used. Further experiments are required to better understand how the concentration of and mechanism by which sulphuric acid and other secondary material becomes mixed with dust particles affects their ice nucleation properties. Since individual atmospheric mineral dust particles are frequently observed to be mixed with such soluble aerosol components (Buseck and Posfai, 1999; Russell et al., 2002; Shi et al., 2008; Sullivan et al., 2007; Sullivan and Prather, 2007), the ice nucleation properties of these mixed particles may represent the best description of a large number fraction of atmospheric aerosol mixing states that can potentially nucleate cirrus or mixed-phase clouds. While sulphuric acid coated mineral dust particles were observed here to be worse IN compared to untreated dust, these mixed particles are still better IN than sulphuric acid solution droplets, which can only nucleate ice homogeneously at temperatures $\leq-38^{\circ} \mathrm{C}$ (Bertram et al., 1996; Hung et al., 2003; Koop et al., 1998; Zuberi et al., 2002).

We propose that concentrated sulphuric acid deposited onto the mineral particle's surface irreversibly alters ice active sites via chemical reactions with various mineral components. This suggests that the manner in which sulphuric acid becomes mixed with the dust will have an important impact on the processed particle's resulting ice nucleation ability. Based on these results, dilute sulphuric acid that is produced during cloud processing in non-evaporating cloud droplets would be expected to have a lesser impact on the dust's freezing ability than concentrated sulphuric acid that is produced through heterogeneous uptake of $\mathrm{SO}_{2}(\mathrm{~g})$ and subsequent oxidation to $\mathrm{H}_{2} \mathrm{SO}_{4}$ in non-activated particles. $\mathrm{H}_{2} \mathrm{SO}_{4}$ produced in this manner may also be quickly neutralized by the uptake of ammonia gas. Similarly, while converting the sulphuric acid coating to ammonium sulphate through exposure to ammonia gas resulted in poorer ice nucleation ability in our study, we were unable to test the effect of directly condensing/mixing ammonium sulphate with the mineral particles. We would expect that ammonium sulphate would have a lesser effect on immersion/condensationmode freezing compared to concentrated sulphuric acid, due to their large differences in acidity and corrosive power. Ammonium sulphate could feasibly be irreversibly dissolved off the particle surface during immersion/condensation-freezing to uncover the active sites, as we have observed for ATD exposed to nitric acid vapour (Sullivan et al., 2010), whereas sulphuric acid condensed using heat appears to induce irreversible chemical damage to the particle surface, based on the observations presented here. ATD particles immersed in an ammonium sulphate solution had reduced immersion/condensation-freezing ability attributed to solute effects alone, implying no alteration of active sites (Zobrist et al., 2008). The potentially important effects that the pathway through which sulphuric acid, ammonium sulphate, and similar secondary components become mixed with mineral dust and other ice nuclei have on the chemically aged particle's resulting ice nucleation properties warrant further investigation.

\section{Conclusions}

The resulting ice nucleation properties of dust particles after a variety of thermochemical treatments focused on sulphuric acid condensation were investigated experimentally. Addition of soluble acidic material to ATD always reduced the fraction of particles that nucleated ice compared to uncoated dust, except for ice nucleation in the immersion/condensation-freezing regime for the lowest temperature sulphuric acid coating. A trend of decreasing IN fraction with increasing soluble material condensed on the particles was observed. Ice nucleation in the deposition regime below water saturation was significantly more impaired by the chemical processing than was the immersion/condensation-freezing regime above water saturation for the same conditions. Highly acidic and corrosive sulphuric acid appears to irreversibly chemically and/or physically modify the mineral particle's surface and iceactive surface sites that are responsible for the untreated dust's high freezing efficiency. The reduction of freezing ability under immersion/condensation-freezing conditions where the coated particle was activated into a droplet before or during freezing - indicates that the dissolution of the 
coating in the droplet did not completely restore the particle's ice nucleation ability. The effects of processing on ice nucleation in the deposition regime are more convoluted, as the coatings may have shifted the ice formation mechanism below water saturation from a deposition mechanism to a condensation-freezing like mechanism where solute effects can play an important role.

The observed enhanced loss of ice nucleation ability after coated particles were heated is attributed to an acceleration of the chemical alteration of surface sites. However, as heat was also used to condense sulphuric acid onto the particle's surface in the coating oven, we cannot discriminate between the effect of the sulphuric acid coating alone, or in combination with heat, on the observed loss of ice nucleation ability. Further experiments that expose dust particles to acidic vapours for longer periods of time without the use of heat are required to separate these effects. Such experiments would address an obvious concern that the use of heat in great excess of atmospheric values introduces additional effects that do not represent atmospheric conditions, versus confirming the alternate hypothesis that heat simply accelerates processes that would already occur under longer atmospheric timescales. Recent experiments in which ATD was exposed to nitric acid vapour at room temperature revealed that while deposition nucleation was impaired by this process, condensation/immersion-freezing above water saturation was unaffected (Sullivan et al., 2010). The different effect on immersion/condensation-regime freezing compared to the sulphuric acid coatings presented here may be due to the effects of heat discussed above, or differences between nitric and sulphuric acid chemistry and reaction products.

The cause of the additional loss of IN ability from exposing the coated particles to ammonia gas is not known. The formation of an aqueous solution following absorption of water was hypothesised to more completely coat the particle's active sites, while either reducing the ability of the acid to chemically alter these sites through dilution, or facilitating chemical reactions that produce or reveal new active sites and low volatility products after the addition of heat. However, exposing coated particles to ammonia without the water bath also reduced $f_{\mathrm{IN}}$ more than the coating alone did. The roles that water vapour and ammonia play in these processes and the resulting ice nucleation properties are atmospherically relevant, not well understood, and warrant further investigation.

These results add to the growing body of work indicating that in many cases the addition of soluble secondary material can significantly reduce the ice nucleation ability of mineral dust particles, both below and above water saturation (Archuleta et al., 2005; Cziczo et al., 2009; Eastwood et al., 2009; Möhler et al., 2008; Niedermeier et al., 2010a; Sullivan et al., 2010). They have revealed that while both modes are irreversibly impaired by the condensation of concentrated acid, the deposition regime is significantly more sensitive to such chemical processing. This suggests that atmospheric ice production below water saturation can potentially be prohibited when atmospheric ice nuclei become mixed with secondary pollutants.

Acknowledgements. The FROST-2 measurement campaign was conducted as part of the Helmholtz Virtual Institute "Aerosol-Cloud Interactions" and the DFG project HE 939/21-1. This research was also financially supported by the Integration of European Simulation Chambers for Investigating Atmospheric Processes (EUROCHAMP) program funded within the EC 6th Framework Program, and by the US National Science Foundation (Grant ATM-0611936). We thank all the participants of the FROST-2 campaign for their support and valuable discussions.

Edited by: D. Knopf

\section{References}

Abbatt, J. P. D.: Interactions of atmospheric trace gases with ice surfaces: Adsorption and reaction, Chem. Rev., 103, 4783-4800, 2003.

Abbatt, J. P. D., Benz, S., Cziczo, D. J., Kanji, Z., Lohmann, U., and Möhler, O.: Solid ammonium sulfate aerosols as ice nuclei: A pathway for cirrus cloud formation, Science, 313, 1770-1773, 2006.

Archuleta, C. M., DeMott, P. J., and Kreidenweis, S. M.: Ice nucleation by surrogates for atmospheric mineral dust and mineral dust/sulfate particles at cirrus temperatures, Atmos. Chem. Phys., 5, 2617-2634, doi:10.5194/acp-5-2617-2005, 2005.

Baker, M. B.: Cloud microphysics and climate, Science, 276, 10721078, 1997.

Bertram, A. K., Patterson, D. D., and Sloan, J. J.: Mechanisms and temperatures for the freezing of sulfuric acid aerosols measured by FTIR extinction spectroscopy, J. Phys. Chem., 100, 23762383, 1996.

Buck, A. L.: New equations for computing vapor-pressure and enhancement factor, J. Appl. Meteorol., 20, 1527-1532, 1981.

Buseck, P. R. and Posfai, M.: Airborne minerals and related aerosol particles: Effects on climate and the environment, Proc. Natl. Acad. Sci. USA, 96, 3372-3379, 1999.

Cantrell, W. and Heymsfield, A.: Production of ice in tropospheric clouds - A review, B. Am. Meteorol. Soc., 86, 795-807, 2005.

Connolly, P. J., Möhler, O., Field, P. R., Saathoff, H., Burgess, R., Choularton, T., and Gallagher, M.: Studies of heterogeneous freezing by three different desert dust samples, Atmos. Chem. Phys., 9, 2805-2824, doi:10.5194/acp-9-2805-2009, 2009.

Cziczo, D. J., Froyd, K. D., Gallavardin, S. J., Moehler, O., Benz, S., Saathoff, H., and Murphy, D. M.: Deactivation of ice nuclei due to atmospherically relevant surface coatings, Environ. Res. Lett., 4, 044013, doi:10.1088/1748-9326/4/4/044013, 2009.

DeMott, P. J., Cziczo, D. J., Prenni, A. J., Murphy, D. M., Kreidenweis, S. M., Thomson, D. S., Borys, R., and Rogers, D. C.: Measurements of the concentration and composition of nuclei for cirrus formation, Proc. Natl. Acad. Sci. USA, 100, 14655-14660, 2003a.

DeMott, P. J., Sassen, K., Poellot, M. R., Baumgardner, D., Rogers, D. C., Brooks, S. D., Prenni, A. J., and Kreidenweis, S. M.: African dust aerosols as atmospheric ice nuclei, Geophys. Res. Lett., 30, L07808, doi:10.1029/2003GL017410, 2003 b. 
DeMott, P. J., Petters, M. D., Prenni, A. J., Carrico, C. M., Kreidenweis, S. M., Collett, J. L., and Moosmuller, H.: Ice nucleation behavior of biomass combustion particles at cirrus temperatures, J. Geophys. Res., 114, D16205, doi:10.1029/2009jd012036, 2009.

Eastwood, M. L., Cremel, S., Gehrke, C., Girard, E., and Bertram, A. K.: Ice nucleation on mineral dust particles: Onset conditions, nucleation rates and contact angles, J. Geophys. Res., 113, D22203, doi:10.1029/2008jd010639, 2008.

Eastwood, M. L., Cremel, S., Wheeler, M., Murray, B. J., Girard, E., and Bertram, A. K.: Effects of sulfuric acid and ammonium sulfate coatings on the ice nucleation properties of kaolinite particles, Geophys. Res. Lett., 36, L02811, doi:10.1029/2008g1035997, 2009.

Garland, E. R., Rosen, E. P., Clarke, L. I., and Baer, T.: Structure of submonolayer oleic acid coverages on inorganic aerosol particles: evidence of island formation, Phys. Chem. Chem. Phys., 10, 3156-3161, 2008.

Herich, H., Tritscher, T., Wiacek, A., Gysel, M., Weingartner, E., Lohmann, U., Baltensperger, U., and Cziczo, D. J.: Water uptake of clay and desert dust aerosol particles at sub- and supersaturated water vapor conditions, Phys. Chem. Chem. Phys., 11, 7804-7809, 2009.

Hung, H. M., Malinowski, A., and Martin, S. T.: Kinetics of heterogeneous ice nucleation on the surfaces of mineral dust cores inserted into aqueous ammonium sulfate particles, J. Phys. Chem. A, 107, 1296-1306, 2003

Jimenez, J. L., Jayne, J. T., Shi, Q., Kolb, C. E., Worsnop, D. R., Yourshaw, I., Seinfeld, J. H., Flagan, R. C., Zhang, X. F., Smith, K. A., Morris, J. W., and Davidovits, P.: Ambient aerosol sampling using the Aerodyne Aerosol Mass Spectrometer, J. Geophys. Res., 108, 8425, doi:10.1029/2001JD001213, 2003.

Kanji, Z. A., Florea, O., and Abbatt, J. P. D.: Ice formation via deposition nucleation on mineral dust and organics: dependence of onset relative humidity on total particulate surface area, Environ. Res. Lett., 3, 025004, doi:10.1088/1748-9326/3/2/025004, 2008.

Knopf, D. A. and Koop, T.: Heterogeneous nucleation of ice on surrogates of mineral dust, J. Geophys. Res., 111, D12201, doi:10.1029/2005JD006894, 2006.

Koehler, K.: The impact of natural dust aerosol on warm and cold cloud formation, Atmospheric Science, Colorado State University, Fort Collins, 208 pp., 2007.

Koehler, K., Kreidenweis, S. M., DeMott, P. J., Petters, M. D., Prenni, A. J., and Carrico, C. M.: Hygroscopicity and cloud droplet activation of mineral dust aerosol, Geophys. Res. Lett., 36, L08805, doi:10.1029/2009GL037348, 2009.

Koop, T., Ng, H. P., Molina, L. T., and Molina, M. J.: A new optical technique to study aerosol phase transitions: The nucleation of ice from H2SO4 aerosols, J. Phys. Chem. A, 102, 8924-8931, 1998.

Lasaga, A. C.: Fundamental approaches in describing mineral dissolution and precipitation rates, in: Chemical Weathering Rates of Silicate Minerals, Reviews in Mineralogy, Mineralogical Society America, Washington, USA, 23-86, 1995.

Lohmann, U. and Feichter, J.: Global indirect aerosol effects: a review, Atmos. Chem. Phys., 5, 715-737, doi:10.5194/acp-5-7152005, 2005.

Marcolli, C., Gedamke, S., Peter, T., and Zobrist, B.: Efficiency of immersion mode ice nucleation on surrogates of mineral dust, Atmos. Chem. Phys., 7, 5081-5091, doi:10.5194/acp-7-5081-
2007, 2007.

Martin, S. T.: Phase transitions of aqueous atmospheric particles, Chem. Rev., 100, 3403-3453, 2000.

Möhler, O., Field, P. R., Connolly, P., Benz, S., Saathoff, H., Schnaiter, M., Wagner, R., Cotton, R., Krämer, M., Mangold, A., and Heymsfield, A. J.: Efficiency of the deposition mode ice nucleation on mineral dust particles, Atmos. Chem. Phys., 6, 3007-3021, doi:10.5194/acp-6-3007-2006, 2006.

Möhler, O., Benz, S., Saathoff, H., Schnaiter, M., Wagner, R., Schneider, J., Walter, S., Ebert, V., and Wagner, S.: The effect of organic coating on the heterogeneous ice nucleation efficiency of mineral dust aerosols, Environ. Res. Lett., 3, 025007, doi:10.1088/1748-9326/3/2/025007, 2008.

Niedermeier, D., Hartmann, S., Shaw, R. A., Covert, D., Mentel, T. F., Schneider, J., Poulain, L., Reitz, P., Spindler, C., Clauss, T., Kiselev, A., Hallbauer, E., Wex, H., Mildenberger, K., and Stratmann, F.: Heterogeneous freezing of droplets with immersed mineral dust particles - measurements and parameterization, Atmos. Chem. Phys., 10, 3601-3614, doi:10.5194/acp-10-36012010, 2010a.

Niedermeier, D., Hartmann, S., Wex, H., Clauss, T., Kiselev, A., Sullivan, R. C., DeMott, P. J., Petters, M. D., Reitz, P., Schneider, J., Mikhailov, E., Reimann, B., Bundke, U., Stetzer, O., Sierau, B., Shaw, R. A., Mentel, T. F., and Stratmann, F.: Experimental study of the role of chemical and physical surface processing on the IN ability of mineral dust particles, Atmos. Chem. Phys. Discuss., in preparation, 2010b.

Petters, M. D. and Kreidenweis, S. M.: A single parameter representation of hygroscopic growth and cloud condensation nucleus activity, Atmos. Chem. Phys., 7, 1961-1971, doi:10.5194/acp-71961-2007, 2007.

Petters, M. D. and Kreidenweis, S. M.: A single parameter representation of hygroscopic growth and cloud condensation nucleus activity - Part 2: Including solubility, Atmos. Chem. Phys., 8, 6273-6279, doi:10.5194/acp-8-6273-2008, 2008.

Petters, M. D., Parsons, M. T., Prenni, A. J., DeMott, P. J., Kreidenweis, S. M., Carrico, C. M., Sullivan, A. P., McMeeking, G. R., Levin, E., Wold, C. E., Collett, J. L., and Moosmuller, H.: Ice nuclei emissions from biomass burning, J. Geophys. Res., 114, D07209, doi:10.1029/2008jd011532, 2009.

Phillips, V. T. J., DeMott, P. J., and Andronache, C.: An empirical parameterization of heterogeneous ice nucleation for multiple chemical species of aerosol, J. Atmos. Sci., 65, 2757-2783, 2008.

Rogers, D. C.: Development of a continuous flow thermal gradient diffusion chamber for ice nucleation studies, Atmos. Res., 22, 149-181, doi:10.1016/0169-8095(88)90005-1, 1988.

Rogers, D. C., DeMott, P. J., Kreidenweis, S. M., and Chen, Y. L.: A continuous-flow diffusion chamber for airborne measurements of ice nuclei, J. Atmos. Ocean. Tech., 18, 725-741, 2001.

Russell, L. M., Maria, S. F., and Myneni, S. C. B.: Mapping organic coatings on atmospheric particles, Geophys. Res. Lett., 29, 1779, doi:10.1029/2002GL014874, 2002.

Salam, A., Lohmann, U., and Lesins, G.: Ice nucleation of ammonia gas exposed montmorillonite mineral dust particles, Atmos. Chem. Phys., 7, 3923-3931, doi:10.5194/acp-7-3923-2007, 2007.

Shantz, N. C., Leaitch, W. R., Phinney, L., Mozurkewich, M., and Toom-Sauntry, D.: The effect of organic compounds on the 
growth rate of cloud droplets in marine and forest settings, Atmos. Chem. Phys., 8, 5869-5887, doi:10.5194/acp-8-5869-2008, 2008.

Shi, Z., Zhang, D., Hayashi, M., Ogata, H., Ji, H., and Fujiie, W.: Influences of sulfate and nitrate on the hygroscopic behaviour of coarse dust particles, Atmos. Environ., 42, 822-827, 2008.

Stith, J. L., Ramanathan, V., Cooper, W. A., Roberts, G. C., DeMott, P. J., Carmichael, G., Hatch, C. D., Adhikary, B., Twohy, C. H., Rogers, D. C., Baumgardner, D., Prenni, A. J., Campos, T., Gao, R., Anderson, J., and Feng, Y.: An overview of aircraft observations from the Pacific Dust Experiment campaign, J. Geophys. Res., 114, D05207, doi:10.1029/2008JD010924, 2009.

Sullivan, R. C., Guazzotti, S. A., Sodeman, D. A., and Prather, K. A.: Direct observations of the atmospheric processing of Asian mineral dust, Atmos. Chem. Phys., 7, 1213-1236, doi:10.5194/acp-7-1213-2007, 2007.

Sullivan, R. C. and Prather, K. A.: Investigations of the diurnal cycle and mixing state of oxalic acid in individual particles in Asian aerosol outflow, Environ. Sci. Technol., 41, 8062-8069, 2007.

Sullivan, R. C., Moore, M., Petters, M. D., Kreidenweis, S. M., Roberts, G., and Prather, K. A.: Timescale for hygroscopic conversion of mineral dust particles after heterogeneous reaction with nitric acid, Phys. Chem. Chem. Phys., 11, 7826-7837, 2009a.

Sullivan, R. C., Moore, M. J. K., Petters, M. D., Kreidenweis, S. M., Roberts, G. C., and Prather, K. A.: Effect of chemical mixing state on the hygroscopicity and cloud nucleation properties of calcium mineral dust particles, Atmos. Chem. Phys., 9, 33033316, doi:10.5194/acp-9-3303-2009, 2009b.

Sullivan, R. C., Minambres, L., DeMott, P. J., Prenni, A. J., Carrico, C. M., Levin, E. J. T., and Kreidenweis, S. M.: Chemical processing does not always impair heterogeneous ice nucleation of mineral dust particles, Geophys. Res. Lett., in press, doi:10.1029/2010GL045540, 2010.
Vali, G.: Atmospheric Ice Nucleation - A Review, J. Rech. Atmos., 19, 105-115, 1985.

Vali, G.: Freezing rate due to heterogeneous nucleation, J. Atmos. Sci., 51, 1843-1856, 1994.

Vali, G.: Repeatability and randomness in heterogeneous freezing nucleation, Atmos. Chem. Phys., 8, 5017-5031, doi:10.5194/acp-8-5017-2008, 2008.

Vlasenko, A., Sjogren, S., Weingartner, E., Gaggeler, H. W., and Ammann, M.: Generation of submicron Arizona Test Dust aerosol: Chemical and hygroscopic properties, Aerosol Sci. Technol., 39, 452-460, 2005.

Welti, A., Lüönd, F., Stetzer, O., and Lohmann, U.: Influence of particle size on the ice nucleating ability of mineral dusts, Atmos. Chem. Phys., 9, 6705-6715, doi:10.5194/acp-9-6705-2009, 2009.

Wex, H., Petters, M. D., Carrico, C. M., Hallbauer, E., Massling, A., McMeeking, G. R., Poulain, L., Wu, Z., Kreidenweis, S. M., and Stratmann, F.: Towards closing the gap between hygroscopic growth and activation for secondary organic aerosol: Part 1 Evidence from measurements, Atmos. Chem. Phys., 9, 39873997, doi:10.5194/acp-9-3987-2009, 2009.

Zimmermann, F., Weinbruch, S., Schutz, L., Hofmann, H., Ebert, M., Kandler, K., and Worringen, A.: Ice nucleation properties of the most abundant mineral dust phases, J. Geophys. Res., 113, D23204, doi:10.1029/2008jd010655, 2008.

Zobrist, B., Marcolli, C., Peter, T., and Koop, T.: Heterogeneous ice nucleation in aqueous solutions: the role of water activity, J. Phys. Chem. A, 112, 3965-3975, 2008.

Zuberi, B., Bertram, A. K., Cassa, C. A., Molina, L. T., and Molina, M. J.: Heterogeneous nucleation of ice in (NH4)(2) $\mathrm{SO}_{4}-\mathrm{H}_{2} \mathrm{O}$ particles with mineral dust immersions, Geophys. Res. Lett., 29, 1504, doi:10.1029/2001GL014289, 2002. 